\title{
Management control packages in family businesses: a configurational approach
}

\author{
Stefanie Einhorn ${ }^{1} \cdot$ Xaver Heinicke ${ }^{1} \cdot$ Thomas W. Guenther $^{1} \mathbb{B}$
}

Published online: 3 October 2020

(C) The Author(s) 2020

\begin{abstract}
This study uses survey data from top managers to explore how operational (e.g., cost types and cost center accounting) and strategically oriented (e.g., strategic and business planning) management accounting (MA) practices, diagnostic and interactive use of performance measures, and cultural controls are combined (management control package) to achieve high firm performance in family businesses (FBs). In previous research, such management control (MC) packages have received limited attention even though they offer an opportunity to reveal more information on the adoption of MA practices, use of performance measures, and MCs in FBs than analyses of individual control mechanisms. We chose a qualitative comparative analysis (QCA) because this method allows for explicitly addressing the three major challenges of configurational theory: asymmetry, conjunctional causation, and equifinality. By applying QCA, our study identifies six equifinal MC packages (i.e., different configurations of MA practices, types of use, and cultural controls with similar associations with firm performance) and, thus, provides an exploratory approach to describe more complex MA and MC designs that are empirically observable. By further analyzing these MC packages with additional information on the intensity of competition, the intensity of attention focusing, the interpretation of information by top management, and the organizational culture, this study extends the existing literature on FBs. The key finding of our analysis is that, regardless of their business environment, successful FBs place a very strong emphasis on cultural controls and/or have a high degree of interactive use of performance measures to steer their business.
\end{abstract}

Keywords Management control package $\cdot$ Family business $\cdot$ Configurational research · Qualitative comparative analysis · Firm performance

JEL Classification M10 $\cdot$ M14 $\cdot$ M21 $\cdot$ M41

Thomas W. Guenther

Thomas.Guenther@tu-dresden.de

Extended author information available on the last page of the article 


\section{Introduction}

Management accounting (MA) and management controls (MCs) enable more effective management of businesses and, thus, are considered essential elements and crucial factors in the creation of a competitive advantage and, ultimately, firm performance (Simons 1995; Chenhall 2003). "MA refers to a collection of practices [...]"1 (Chenhall 2003, p. 129). In our study, we define MA practices as operational (e.g., cost type accounting and cost center accounting) and strategically oriented (e.g., strategic and business planning) tools that can provide management with the information necessary to better plan and assess actions, subsequently anticipate the future, and support decision making (Roberts and Scapens 1985; Chenhall 2003). The distinction between operational and strategically oriented MA practices is relevant because smaller family businesses (FBs) tend to adopt more operational MA practices, whereas larger FBs tend to adopt more strategically oriented MA practices (see Hiebl et al. 2013). In contrast, MCs such as cultural controls are not used primarily as an information system to support decisions but to ensure that employee behavior is in accordance with the organization's goals (Simons 1995; Malmi and Brown 2008; Merchant and Van der Stede 2017). Cultural controls are defined as the communication of desired and undesired behavior and the sharing of values and norms that determine internal social conventions (Bedford and Malmi 2015; Merchant and Van der Stede 2017). Despite the unambiguous role of MA practices and MCs in firms in general and the significant role of FBs in the global economy, especially in German-speaking countries ${ }^{2}$ (IFERA 2003; Family Firm Institute 2017; The Foundation for Family Business 2019), the field of MA practices and MCs and particularly their combination (i.e., MC packages) in FBs are regarded as underexplored (e.g., Helsen et al. 2017; Songini et al. 2018).

Previous studies have consistently revealed that FBs adopt fewer MA practices (e.g., see the reviews by Senftlechner and Hiebl 2015; Helsen et al. 2017; Songini et al. 2018) because a stewardship-oriented behavior has been stated as having an essential implication for MA practices (Helsen et al. 2017). Stewardship behavior refers to social ties between owning family and nonfamily employees that foster and empower employees' commitment and motivation (Zahra et al. 2008). Therefore, the adoption of MA practices may lower stewardship behavior (Corbetta and Salvato 2004). Thus, FBs adopt fewer MA practices and more aspects of social controls (Helsen et al. 2017). Social controls are defined as controls that address "[...] the emotional, non-rational, affective elements within employees" (Ray 1986, p. 288 f.) and include the core values, beliefs, and norms that comprise the manageable aspects of organizational culture (Tessier and Otley 2012). Following this definition, the concept of social controls considerably overlaps the concept of cultural controls.

\footnotetext{
1 Chenhall (2003, p. 129) distinguishes between MA and management accounting system (MAS) by completing the sentence "[...] while MAS refers to the systematic use of MA to achieve some goal." However, in our study, we do not examine MAS but only MA as a collection of practices in a package.

${ }^{2}$ For example, depending on the definition of family controlled firms, $90 \%$ of all German firms are FBs, and FBs employ 58\% of the German workforce (The Foundation for Family Business 2019).
} 
Cultural controls may serve to empower employees through the definition, information, and communication of collective norms and values in mission statements or codes of conduct. Therefore, employees are aware of and are inspired by a firm's norms and values. However, most studies neglect to consider cultural controls as crucial factors (see Dekker et al. 2015; Helsen et al. 2017; Songini et al. 2018). The communication of clear, consistent, and guiding values shaped by the owning family members and the attachment to the firm's history, which often reflect the founder's vision, create a strong organizational culture and an advantage for the firm when the environment changes (Hall et al. 2001; Denison et al. 2004; Zahra et al. 2008). However, a weaker reliance on strict controls, rules, and procedures has no negative effect on the profitability of FBs (Vallejo 2009).

Stewardship behavior fosters employee involvement, which is associated with "[...] high levels of information exchange and social interaction [...]" (Madison et al. 2017, p. 349). This involvement can be encouraged by the interactive use of performance measures (PMs), which enables discussions in meetings and debates regarding the underlying data and ties the firm together. In addition to interactive use, Simons (1995) describes another type of use-diagnostic use. Diagnostic use reflects the extent to which top managers use PMs to track and monitor critical success factors. Previous research has addressed the differences between simply adopting (i.e., an MA practice is implemented but hardly used or not used at all) and emphasizing the use of MA or MCs (e.g., Bourne et al. 2005; Henri 2006). However, limited evidence is available regarding the different types of use (i.e., diagnostic and interactive) in FBs (with the exception of Acquaah 2013). We measured diagnostic and interactive use as the use of a performance measurement system with PMs provided by operational and strategically oriented MA practices (in short, the use of PMs).

Although much has been learned about MA practices and MCs in FBs, an understanding of the association among the adoption of MA practices, the two types of use, and cultural controls is lacking because these control mechanisms have been analyzed individually (e.g., Daily and Dollinger 1992; Filbeck and Lee 2000; Blumentritt 2006; García Pérez de Lema and Duréndez 2007; Speckbacher and Wentges 2012; Dekker et al. 2015). However, MA practices and MCs are not isolated mechanisms (Dent 1990; Fisher 1998; Malmi and Brown 2008) but "[...] interwoven component[s] of an organizational control package" (Bedford and Malmi 2015, p. 2). Bedford et al. (2016, p. 12) state that "[...] without empirical evidence it remains less than clear whether all [MA practices and MCs] found to be relevant separately are in fact relevant when examined simultaneously as a package." MA practices and MCs that have an incremental benefit in isolation may not necessarily be relevant for a high performing firm when investigated as a broad set of MA practices and MCs (Bedford et al. 2016). Therefore, the question arises as to whether MA practices, types of use, and cultural controls separately found to be relevant have an incremental benefit for achieving high firm performance when examined as a package.

To determine the MA practices, type of use, and cultural controls that are relevant and redundant, we examine simultaneously a set of two types of MA practices 
(i.e., operational and strategically oriented MA practices), two types of use ${ }^{3}$ (i.e., interactive or diagnostic use), and the emphasis on cultural controls. Therefore, we provide a discussion of configurations that is consistent with configuration theory and appears in the literature under the expression, "MC as a package" (e.g., Malmi and Brown 2008; Grabner and Moers 2013; Bedford et al. 2016). The term "package" goes back to Otley (1980) and includes accounting information (referring to MA practices) and organizational controls (referring to cultural controls). Recent MA and MC research differentiates between MC as a package and an MC system. $\mathrm{MC}$ as a package refers to a set of MA practices, types of use, and $\mathrm{MCs},{ }^{4}$ which are sometimes only very loosely coupled, whereas an MC system is characterized by designed interdependencies among MA practices, types of use, and MCs (Grabner and Moers 2013).

Thus, the theoretical problem addressed in our paper refers to a combination of different MA practices and cultural controls (i.e., configuration of controls) instead of focusing on one specific MA practice or MC. This theoretical problem addresses the practical problem faced by managers who have to decide how to design and use a set of different MA practices or MCs and are unable to design or use MA practices and MCs in isolation (e.g., focus only on budgeting as an operational MA practice without considering cultural controls or type of use). We address these problems using a two-step approach.

First, we investigate how a set of MA practices, the use of PMs, and cultural controls combined as an MC package achieve high firm performance in FBs. To determine the MA practices, type of use, and cultural controls that are relevant or redundant for high firm performance and, thus, complex configurations of MC packages, a qualitative comparative analysis (QCA) is an appropriate configurational approach (Bedford et al. 2016). QCA allows us to examine the empirical problem underlying the theoretical and practical problems of how configurations of different MA practices and MCs can be adequately and empirically explored. QCA explicitly addresses the following three major challenges of configurational theory: asymmetry, conjunctional causation, and equifinality. For example, as a set-theoretic method, QCA enables the investigation of asymmetry and, thus, allows for a separate analysis of high and low firm performance configurations, enabling deeper insights (Ragin 2000; Schneider and Wagemann 2012; Bedford and Sandelin 2015). Our theoretical arguments are tested on a cross-sectional sample of 66 FBs by considering configurations of different MA practices, two types of use, and cultural controls with firm size as a crucial contextual factor (Hiebl et al. 2013).

Second, because we use a case-oriented research method, we further analyze the cases and provide deeper insights into our results (i.e., MC packages) by investigating additional variables that offer information on the environmental context

\footnotetext{
3 The two types of use refer to a performance measurement system with PMs that are typically delivered by underlying MA practices. For example, according to Flamholtz (1983), measurement systems include accounting systems with measures (i.e., MA practices) and information systems.

4 " [...] MC as a package represents the complete set of control practices in place, regardless of whether the MC practices are interdependent and/or the design choices take interdependencies into account" (Grabner and Moers 2013, p. 408).
} 
(intensity of price and quality competition) in combination with how intensively top management pays attention to information from PMs. Previous research on FBs has mainly investigated the degree of family involvement (measured by FIBER ${ }^{5}$ or F-PEC (Family-Power, Experience, Culture)) and its impact on revenue, growth, capital structure, and perceived performance (Rutherford et al. 2008) or the effect of family involvement on the adoption of MA practices or MCs and firm performance (e.g., Tsao et al. 2009; Dekker et al. 2015). However, how an FB's environmental context, especially competitive situations, affects the configuration of MA practices and MCs and, eventually, firm performance remains unclear. A competitive situation as a part of the perceived environmental uncertainty is known as an important driver of MC packages in firms (e.g., Khandwalla 1972; Amat et al. 1994). Therefore, in our exploratory study, we build on the findings reported in the general MA and MC literature and FB research by offering additional insights into the effects of MC packages on firm performance and note that the environmental context and, in particular, competitive situations influence FBs. In this manner, our study examines the MC package of FBs from an external perspective (e.g., driven by contextual factors, such as competition) and expands previous studies that mainly examine their results from an internal perspective (e.g., degree of family involvement as the key variable).

This paper contributes to the literature on MA and MC in FBs in three ways. First, this study extends the MA and MC literature on FBs using QCA to provide information on the relevance of the adoption of MA practices, the two types of use, and the emphasis on cultural controls within an MC package. Our study reveals that in previous studies, not all MA practices observed to be or not to be individually associated with firm performance are necessarily relevant for achieving high firm performance when examined as a part of an MC package, which refers to the joint effect of MA practices and MCs (conjunctional causation). However, our findings show that the interactive use of PMs and/or cultural controls are always present in FBs achieving high firm performance and, thus, are crucial elements of MC packages in successful FBs. Thus, this study represents the first attempt to explicitly investigate MC packages in FBs and develops a more fine-grained understanding of the specific roles of cultural controls and interactive use in FBs supported by stewardship theory as the theoretical foundation. Second, building on configuration theory, this study explores six alternative MC packages in FBs, which implies equifinality because various MC packages coexist and lead to high firm performance (Drazin and Van De Ven 1985; Gresov and Drazin 1997; Fiss 2011). Therefore, this study contributes by providing an enhanced understanding that FBs can choose between multiple, equally successful configurations in similar, competitive situations. Thus, FBs are able to combine MA practices and cultural controls within configurations in different ways (Bedford et al. 2016). The empirical findings extend existing results by describing more complex MA and MC designs that arise in practice. Third, in contrast to prior research

\footnotetext{
5 "FIBER is the short form for the following five dimensions: Family control and influence (F), Identification of family members with the firm (I), Binding social ties (B), Emotional attachment of family members (E), Renewal of family bonds to the firm through dynastic succession (R)" (Hauck et al. 2016, p. 133).
} 
that has mostly focused on high firm performance, the QCA method allows for an examination of both high and low firm performance without assuming symmetry in MC packages. In addition to the identified high firm performance configurations, this study introduces a low-performing configuration and demonstrates the asymmetry of MC configurations.

Thus, our study uses stewardship theory as the theoretical foundation and configuration theory as the methodological, theoretical foundation to address the theoretical problem of the combination of different MA practices, two types of use, and cultural controls instead of focusing on one specific MA practice or MC. Through this approach, this study expands the current understanding of the choice and consequences of combinations of MA practices and cultural controls in the competitive context of FBs.

\section{Theoretical background}

\subsection{Stewardship theory and organizational culture}

Research on FBs often addresses stewardship theory (Madison et al. 2016) and assumes that individuals acting as stewards follow an intrinsic desire to serve the organization and experience greater long-term utility in prosocial behavior than short-term, self-interested opportunistic behavior (Davis et al. 1997; Hernandez 2008, 2012). The conditions that may be associated with stewardship in FBs involve commitment to the business and a high degree of family identification, aligned and shared values among the business, the family, and employees, and a focus on the long-term success of the business (Zahra et al. 2008). A high degree of shared commitment to the FB can reinforce a sense of reciprocal altruism and mutual interdependence and foster pro-organizational and prosocial supporting behavior that strengthens long-term organizational objectives (Eddleston et al. 2008; Zahra et al. 2008).

A key aspect of stewardship theory is commitment, which influences individuallevel behavior and firm-level governance (Hernandez 2012; Madison et al. 2016). Commitment ${ }^{6}$ is " $[\ldots]$ defined generally as a psychological link between the employees and their organization [...]" (Vallejo 2009, p. 380). Affective commitment is a special form of commitment that "[...] refers to identification and emotional attachment to the organization [...]" (Vallejo 2009, p. 380) and alignment with firm values and beliefs (Vallejo 2009; Davis et al. 2010). Therefore, commitment with strong ties and shared values encourages particular actions and, thus, stewardship behavior (Vallejo 2009; Davis et al. 2010; Madison et al. 2017).

The establishment of stewardship behavior in a firm is strongly influenced by the leader, who is the owner in the case of FBs (Rhoades and Eisenberger 2002; Zahra et al. 2008; Vallejo 2009). Previous studies (e.g., Barsade 2002; Sy et al.

\footnotetext{
6 Vallejo (2009) distinguishes among the following three forms of commitment: affective, continuance, and normative commitment. The theoretical focus of our study is primarily on affective commitment.
} 
2005) reveal a "[...] social contagion of affect [...]" (Zahra et al. 2008, p. 1038). This finding indicates that the preference of the owning family for (affective) commitment can cause similar (affective) behavior among nonfamily employees. ${ }^{7}$ Thus, nonfamily employees are emotionally associated with the FB and often act in the interest of the family and firm without strict rules and procedures (Miller and Le Breton-Miller 2006; Zahra et al. 2008; Vallejo 2009; Madison et al. 2017).

To enable stewardship behavior, the owning family uses stewardship governance (Madison et al. 2017), which refers to "[...] stewardship-oriented practices designed to engage and bond members to the organization" (Zahra et al. 2008, p. 1036) to obtain collective benefits (Hernandez 2012). Thus, stewardship behavior is motivated by the involvement of employees and individual empowerment in a collective work environment (Corbetta and Salvato 2004; Madison et al. 2017) rather than an agency-based governance set that emphasizes direct financial controls and supervisory systems (Davis et al. 1997). The involvement of employees is associated with "[...] high levels of information exchange and social interaction [...]" (Madison et al. 2017, p. 349). Thus, stewardship behavior and stewardship governance in an FB enhance firm performance (Gomez-Mejia et al. 2011; Madison et al. 2017) as a weaker reliance on strict controls, rules, and procedures has no negative effect on the profitability of FBs. Vallejo (2009) even reveals that affective commitment creates a profitability advantage for FBs.

The transmitted value of commitment and stewardship-oriented practices shapes not only stewardship behavior among nonfamily employees but also a collective stewardship-oriented culture within the firm (Zahra et al. 2008; Pearson and Marler 2010; Madison et al. 2017). Stewardship culture refers to the loyalty and care of employees in a collective work environment (Zahra et al. 2008). Thus, the culture of the family determines "[...] what individuals within the family businesses do and how they interpret and respond to environmental challenges" (Zahra et al. 2008, p. 1036). Therefore, the family preference shapes the values and norms and, thus, the organizational culture within FBs (Zahra et al. 2008). The organizational culture contains a set of "[...] common beliefs, shared values, norms of behavior, and assumptions that are implicitly accepted and explicitly manifested throughout the organization" (Anthony and Govindarajan 2007, p. 100). Thus, stewardship culture is crucial for creating prosocial behavior and values, including mutual trust (Steier 2001), low information asymmetry, loyalty, altruism (Schulze et al. 2001), clan-based togetherness, strong firm identification, and deep emotional investment (Corbetta and Salvato 2004), which are managed through interaction with employees and communication.

Despite the strong ties and social relations of stewardship behavior, some problems can arise from a stewardship orientation. Given their strong commitment, both family members and nonfamily employees are tied to the FB in the past, present,

\footnotetext{
7 Stewardship behavior can be determined not only across a management team involving family members or nonfamily managers who are "[...] emotionally linked to the family" (Miller and Le BretonMiller 2006, p. 74; see also Hiebl et al. 2013) but also "[...] across all levels of the organization" (Hernandez 2012, p. 175).
} 
and future. This lifelong commitment may lead to strategic stagnation (Miller and Le Breton-Miller 2006). In addition, asymmetric altruism in FBs may lead the owning family to prefer their family members and relatives over nonfamily members in terms of management positions and incentive systems (Schulz et al. 2001, 2002). This preference for the family may lead to nonideal management decisions because of a lack of professional management and know-how (Schulz et al. 2002). Moreover, the risk exists that family members prefer family goals over firm goals and that decision making is not based on rational arguments (Davis et al. 2010). Therefore, altruism and self-control may also create special agency problems in FBs (Schulz et al. 2001, 2002; Songini and Gnan 2015). Another problem could be the different choice of managers ("agents") and owners ("principals") regarding their relationship (Davis et al. 1997). If the owning family chooses a steward relationship but the manager prefers an agency relationship, the manager acts opportunistically to serve his or her interests at the expense of the FB. Davis et al. (1997, p. 40) describe this situation as "[...] an agent will behave as a 'fox in the henhouse' [...]". Such manager behavior may lead the owning family to increase the tracking and monitoring of critical success factors.

However, the behavior within FBs is often constituted by stewardship characteristics, such as commitment, interactions involving knowledge sharing in face-to-face meetings, and a collaborative organizational culture that defines the rules of behavior, directs employees' attention, and guides decisions (Dyer 1988, 2006; Zahra et al. 2008; Duh et al. 2010; Cunningham et al. 2017). Consistent with the theoretical argumentation regarding stewardship behavior, we assume that an advantage of FBs is the adoption of stewardship-oriented practices, such as face-to-face meetings, shared values, and social relations. Thereby, we assume that the FBs in our sample reflect stewardship behavior because of the aforementioned aspects of stewardship culture (similar to a clan culture), such as loyalty, commitment, and care of employees in a collective work environment (Zahra et al. 2008). A clan culture ${ }^{8}$ is often the dominant orientation in FBs (Duh et al. 2010) and represents institutional characteristics, such as an extended family, as a very personal place in which loyalty and commitment hold the firm together with an emphasis on cohesion and human resources (Cameron and Quinn 2011). Our sample firms show a strong emphasis on clan culture (see Sect. 4.1).

\subsection{Management accounting and control and firm performance in family businesses}

FBs typically exhibit stewardship behavior, which affects the practices of involvement and empowerment and, thus, the adoption of MA practices. MA refers to the collection of operational (e.g., cost types and cost center accounting) and

\footnotetext{
${ }^{8}$ The competing values framework consists of four culture types (Quinn and Rohrbaugh 1981). In addition to the clan culture, an adhocracy culture places substantial emphasis on flexibility and external focus and is typified by an entrepreneurial and dynamic workplace. A hierarchical culture places substantial emphasis on control, stability, and internal focus and is typified by a structured and formalized workplace. Finally, a market culture applies to a result-oriented workplace that also emphasizes control and stability.
} 
strategically oriented practices (e.g., strategic and business planning) that can provide information to managers for decision making. Operational and strategically oriented MA practices are assumed to be complements rather than substitutes because operational MA practices are adopted in firms earlier than strategically oriented MA practices (Hiebl et al. 2013).

Several studies have reported that FBs adopt fewer operational and strategically oriented MA practices than non-FBs (NFBs) (e.g., Daily and Dollinger 1992; García Pérez de Lema and Duréndez 2007; Speckbacher and Wentges 2012; Hiebl et al. 2013; Hiebl et al. 2015; Senftlechner and Hiebl 2015) because, given the shared commitment among family members and nonfamily employees with empowerment and involvement, traditional agency problems, ${ }^{9}$ such as moral hazards through information asymmetry, arise only rarely. ${ }^{10}$ For example, García Pérez de Lema and Duréndez (2007) show that FBs establish fewer business monitoring processes, such as cash budgets and planning decision-making processes, than NFBs. Hiebl et al. (2013) find that medium-sized FBs with high family influence adopt fewer operational planning instruments and strategic MA instruments. However, the adoption of fewer MA practices does not inevitably lead to inferior efficiency in FBs (Daily and Dollinger 1992; Speckbacher and Wentges 2012). For example, Daily and Dollinger (1992) investigate formal internal control systems, such as cost control and cost centers. These authors find that FBs adopt fewer operational MA practices but are more successful than NFBs. Speckbacher and Wentges (2012) reveal that FBs adopt fewer strategically oriented MA practices (i.e., Balanced Scorecard-type performance measurement systems) with no impact on firms' long-term survival. Dekker et al. (2015) also consider strategically oriented MA practices (i.e., financial control systems, such as financial planning, and performance evaluation systems) and find that MA practices have no significant effect on firm performance in FBs. In contrast to the general MC literature, which proves the significant, positive impact of MA practices on firm performance (e.g., Chow et al. 1991; Widener 2007; Koufteros et al. 2014), these findings imply that MA practices are less relevant for FBs. Speckbacher and Wentges (2012, p. 43) state that "[w]hile our empirical data provides evidence that family controlled firms make less use of formalised instruments,

\footnotetext{
9 Traditional agency problems, such as adverse selection and moral hazards based on information asymmetry, arise if deviations exist between the goals of the owners ("principal") and those of managers or employees who display self-interested opportunistic behavior ("agents") (Jensen and Meckling 1976; Eisenhardt 1989). An alignment of the goals of the principals and agents can be reached through agent-based governance, such as financial controls, monitoring systems, or incentive systems, but these actions incur agency costs (Fama and Jensen 1983). However, based on the argumentation of stewardship behavior, these traditional agency problems do not arise because the owning family transfers its values to management, or the owning family is a part of management. However, FBs may face special agency problems, such as asymmetric altruism, conflicts among family members, or conflicts between family members as majority shareholders and nonfamily members as minority shareholders (e.g., Schulze et al. 2001; Gomez-Meija et al. 2011; Songini and Gnan 2015).

${ }^{10}$ In addition to the constitution of FBs and family involvement, subsequent generations can also affect the adoption of MA practices (see Lussier and Sonfield 2010; Giovannoni et al. 2011) because succeeding (non) family managers require written and formalized strategic plans to understand the owners' or former family managers' decisions and corporate goals.
} 
it does not show [...] how they compensate for this (e.g., by using other control instruments)."

Stewardship behavior in FBs, particularly involvement-oriented practices in a collective work environment, presents a possible explanation. An involvement-oriented practice consists of information exchange and social interaction with employees (Madison et al. 2017). Upton et al. (2001) reveal that FBs share information, such as performance results or goals, with all employees. Eddleston and Kellermanns (2007) show that a participative strategy process with interactive decision making in which decision makers interact with employees through the free and open exchange of information is positively associated with firm performance. The conclusion reached is that the exchange of information between managers and employees is crucial for FBs. This information exchange is consistent with the interactive use of PMs to enable discussions in meetings, debate underlying data, and tie the firm together. Interactive use captures the extent to which top managers use PMs as a communication tool to stimulate debate and dialogue between management and employees (Simons 1995). In addition to interactive use, Simons (1995) describes another type of usediagnostic use. Diagnostic use reflects the extent to which top managers use PMs to track and monitor critical success factors. Diagnostic use overlaps with agency mechanism, which includes monitoring action (Madison et al. 2017).

This argumentation is consistent with the assumption that simply adopting MA practices does not seem sufficient for achieving high firm performance because both the type and intensity of PM use have a positive impact (Songini and Gnan 2015) and can lead to competitive advantages or more effective management of a business. General MA and MC research has indicated that the type of PM use is particularly important for achieving high firm performance (e.g., Bourne et al. 2005; Henri 2006). However, FB studies have rarely investigated the type of use. As an exception, Acquaah (2013) shows that the indirect effect of the diagnostic and interactive use of PMs on firm performance is positively mediated by the business strategy. The findings of previous studies (e.g., Henri 2006) indicate that interactive and diagnostic use are complements. Therefore, our analysis simultaneously considers both types of use.

In addition to MA practices that mostly serve as information systems, MCs are behavior-oriented and used by managers to ensure that employees' behaviors and decisions are consistent with the organization's goals (Simons 1995; Malmi and Brown 2008; Merchant and Van der Stede 2017). Exemplary studies have often proposed that FBs favor social controls to guide employees' behavior to reach the firms' goals (e.g., Daily and Dollinger 1992; Dekker et al. 2015). Social (or socioideological) controls are defined as communication processes that shape core values, beliefs, and norms and comprise the manageable aspects of organizational culture (Alvesson and Kärreman 2004; Tessier and Otley 2012). Following this definition, the concept of social controls considerably overlaps with the concept of cultural controls but extends further. For instance, training opportunities are also assigned to social controls that are, according to Merchant and Van der Stede (2017), part of the concept of personnel controls. Cultural controls are designed to communicate 
group values and norms and are most effective in firms with social and emotional ties (Bedford and Malmi 2015; Merchant and Van der Stede 2017). As parts of the organizational culture, cultural values and norms can be shared in written codes of conduct or unwritten codes through implicit forms of communication. Cultural controls may serve to empower employees through the definition, information, and communication of collective norms and values. Therefore, employees are aware of and are inspired by the firm's norms and values. This argumentation is consistent with the description of stewardship behavior, suggesting that FBs are guided by the transmission of commitment from family members to nonfamily members, which builds a collaborative organizational culture on the basis of shared values, mindsets, and interpretations as well as interaction and social relations. Moores and Mula (2000) refine this view and note that FBs use a combination of clan and bureaucratic controls. ${ }^{11}$ In our study, bureaucratic controls are differentiated into more operational MA practices, such as cost accounting, and more strategically oriented MA practices, such as strategic and business planning. However, most empirical FB studies have neglected to simultaneously examine different MA practices and, in particular, cultural controls. Therefore, we follow Helsen et al. (2017), who argue that future research should focus on the association between MA practices and cultural controls and their impacts on firm performance.

Thus, because of the creation of stewardship behavior through the transmission of family values, particularly commitment, to employees, the MC of FBs to control and manage nonfamily employees is more interactive and is driven by cultural controls. Hence, we assume that FBs with a clan culture are similar to FBs with stewardship behavior and, thus, use their PMs more interactively and strongly emphasize cultural controls.

\subsection{Configurational research}

In MC research, the contingency and configuration theories (Chenhall 2003; Gerdin and Greve 2004, 2008) have often been used as the theoretical foundation for empirical papers (e.g., Henri 2006; Widener 2007; Fiss 2011; Bedford et al. 2016). However, contingency theory has been challenged for its "reductionist" research approach (Meyer et al. 1993; Grabner and Moers 2013) because only a few influencing variables (i.e., individual analysis of MA practices and MCs) have been examined for their impact on firm performance. A more holistic approach has been discussed based on configuration theory, which is consistent with the analysis of MC packages (Meyer et al. 1993; Gerdin and Greve 2004, 2008). Configuration theory describes organizational phenomena through the formation of configurations (Doty et al. 1993); that is, the environment, the organization, and their structures are

\footnotetext{
11 Clan control mechanisms are means of social control (Alvesson and Kärrman 2004), whereas bureaucratic control tools comprise formal MA practices, such as budgeting or action planning, used to monitor goal achievement and assist managers in making decisions (see Songini and Gnan 2015).
} 
interrelated and can change over time. ${ }^{12}$ The underlying key assumption of configuration theory is the tendency for organizational components to group systematically and form limited numbers in terms of time-stable arrangements (Gersick 1991; Bedford and Malmi 2015). Configurations result from both endogenous and exogenous forces (Bedford and Malmi 2015). Exogenous causes, such as competition and environmental selection, limit the number of viable combinations (Hannan and Freeman 1989; Bedford and Malmi 2015), whereas endogenous pressures reflect the active or proactive seeking of a firm to form arrangements that follow internally consistent logic (Child 1972), suggesting that firms are not distributed extensively across contextual and structural traits but rather tend to colocate around a limited number of empirically identifiable patterns (Bedford and Malmi 2015), and these patterns are assumed to lead to the same outcome (Drazin and Van De Ven 1985; Meyer et al. 1993; Gresov and Drazin 1997; Fisher 1998). From a configurational approach, relationships have been considered in terms of equally effective patterns (i.e., configurations) (Drazin and Van De Ven 1985; Gresov and Drazin 1997; Fiss 2011).

General MC research recently focuses on configuration theory (e.g., Bedford and Malmi 2015; Bedford et al. 2016; Kruis et al. 2016). These empirical studies have shown multiple combinations of MA practices and MCs and the contextual factors that explain outcomes, such as high firm performance. A popular methodological approach in MC configuration research and partly in FB research is QCA. QCA studies in FB research focus on administrative controls, such as governance structure, board, and management composition, and their impact on performance (e.g., Garcia-Castro and Aguilera 2014; González-Cruz and Cruz-Ros 2016; Samara et al. 2017; Samara and Berbegal-Mirabent 2018). However, the field of configurational research on FBs regarding MA practices and cultural controls remains unexplored (see Helsen et al. 2017; Songini et al. 2018). Therefore, in this study, we explore multiple control configurations (i.e., MC packages) and argue that the impact of the adoption of MA practices, the use of PMs, and the emphasis on cultural controls regarding firm performance manifest equifinally, that is, no single dominating configuration of an MC package exists, but different combinations of MA practices, types of use, and cultural controls (e.g., different MC packages) can result in similar high firm performance.

Based on these theoretical insights, our paper is guided by the following research question that focuses on the MC package and an understanding that the association among the focal variables is lacking.

How are the adoption of operational and strategically oriented MA practices, the use of PMs, and the emphasis on cultural controls combined (i.e., MC package) in high-performing FBs?

During the first stage of the analysis, we investigate the MC package of operational and strategically oriented MA practices, the interactive and diagnostic use of

\footnotetext{
12 In the organizational literature, several terms, such as taxonomy, typology, strategic group, archetype, organizational form, or gestalt, are used for configurations. The term configuration refers to a particular arrangement of multiple components, parts, mechanisms, attributes, or elements (Bedford and Malmi 2015).
} 
PMs, and cultural controls as the key variables characterizing the control configurations in FBs. In addition, we include the contextual factor of firm size, which influences the adoption of MA practices (Hiebl et al. 2013), the use of PMs, and the emphasis on cultural controls. Our selection of variables is informed by previous research. For example, Moores and Mula (2000) find that cultural controls-more specifically clan controls with shared values, beliefs, and commitment-prevail in an early life cycle stage of FBs. If FBs move beyond this stage and reach a later life cycle stage, then they adopt more operational and strategically oriented MA practices. Furthermore, larger FBs employ more formalized and strategically oriented performance measurement systems than smaller FBs (Filbeck and Lee 2000; Feldbauer-Durstmüller et al. 2012; Speckbacher and Wentges 2012). The differences in the adoption of MA practices and MCs can be attributed to management's greater need for communication, coordination, and justification in large (family) businesses (Chenhall 2003; Speckbacher and Wentges 2012). Therefore, larger FBs and larger NFBs might converge in their adoption of MA practices and MCs (Speckbacher and Wentges 2012; Hiebl et al. 2013).

The MC packages of the adoption of MA practices, the use of PMs, and the emphasis on cultural controls depend on further contextual factors, such as the intensity of the competition, which is identified in previous studies as a driver of MA practices and the use of PMs (Amat et al. 1994; Chenhall 2003; Songini et al. 2018). However, previous FB research has focused mainly on family involvement as a source of high firm performance (e.g., Anderson and Reeb 2003; Lee 2006; Rutherford et al. 2008; O'Boyle et al. 2012) and of adoption of MA practices (e.g., Daily and Dollinger 1992; Felbauer-Durstmüller et al. 2012; Speckbacher and Wentges 2012). This more internal perspective neglects how the FB context-especially the competitive situation-affects an MC package and eventually firm performance. Therefore, as the second stage of our explorative analysis, we use the advantage of QCA as a case-oriented approach and add further contextual factors, such as the intensity of price and quality competition, the intensity of attention and interpretation of information by top management, and the type of organizational culture, to further explore the resulting MC packages for high-performing FBs.

\section{Research design and method}

\subsection{Data collection and sampling}

Data were collected using a survey instrument. ${ }^{13}$ The target sample of 2,452 firms was randomly selected and contained German firms with sales ranging between 20 million and 1 billion Euros, including 631 FBs and 1821 NFBs. Furthermore, the sample is restricted to enterprises that operate in trade, service, and production industries. A comprehensive pretest of the survey instrument was conducted

\footnotetext{
13 The original survey instrument was developed by the third author and another researcher and was used for two other papers with different content that addressed all SMEs of the original sample.
} 
with 16 experts, including researchers and top managers. In 2011, a cover letter was sent along with the questionnaire to one member of the top management team (CEO, CFO, or general manager) of each targeted firm. Furthermore, to increase the response rate, a follow-up reminder letter with access to the online version of the questionnaire was sent. The mailing process resulted in a total response rate of 11.26 percent (276 responses) and an FB response rate of 10.64 percent (66 usable responses). ${ }^{14}$ Our sample was reduced to 66 firms because of our specific research interest in FBs only and missing financial data in the AMADEUS database resulting from nonmandatory financial disclosure for most sample firms. However, archival data are essential to calculate the three-year average return on assets (ROA) for firm performance. ${ }^{15}$ We followed Fiss (2011) and did not impute missing values for our outcome variable (the average ROA) because the imputation of missing values may bias configurations. We apply an involvement definition of FB (Prencipe et al. 2014) regarding family ownership and define "[a] company of any size is a family business if: [t]he majority of decision-rights [are indirectly or directly] in the possession of [a family member[s]], or [...] of [a] person[s] who acquired the share capital of the company [...]"16 (The Foundation for Family Businesses 2016). Previous studies use a similar family controlled definition of FBs (e.g., Garcia-Pérez de Lema and Duréndez 2007; Miller and Le Breton-Miller 2006).

Panels A to E in Table 1 show the descriptive statistics for our sample and the unit response bias tests. Consistent with Armstrong and Overton (1977), we found no significant differences in construct means between early (before follow-up) and late respondents, indicating no response bias (see Panel $\mathrm{C}$ in Table 1). To assess the nonresponse bias, we compared financial characteristics, such as ROA, profit margins, and sales of respondents and nonrespondents of FBs. Panels D and E in Table 1 indicate that response bias is not a major concern in this study, although our sample firms are larger in terms of sales $(\mathrm{p}<0.05)$ than the target sample.

\subsection{Research methodology}

"Even with very large samples, too many attributes can make it difficult to identify commonalities between cases resulting in configurations that are unique to single empirical observations" (Bedford and Sandelin 2015, p. 12). Therefore, in this

\footnotetext{
14 Van der Stede et al. (2006) report a continuous decline in response rates in MA and other fields, such as organizational research, because of time and job pressures.

15 Under German law, the analyzed FBs do not have to disclose financial reports. Therefore, our analysis depends on voluntarily disclosed financial accounting data.

${ }^{16}$ The Foundation for Family Businesses (2016) applies a stricter definition of FBs and adds: "[a] company of any size is a family business if: [...] At least one representative of the family or kin is formally involved in the governance of the company." This part of the definition is not a necessary condition of our FB definition because we focus only on ownership. Therefore, we excluded this part of the definition. "This definition also includes family businesses that have not yet completed the first generation transfer [and] [...] sole proprietors and self-employed (if a legal entity exists that can be transferred to the next generation)" (The Foundation for Family Businesses 2016). Therefore, the intention to transfer to the next family generation is sufficient to constitute an FB, and founder-run firms are special cases of FBs (Klein et al. 2005).
} 
Table 1 Demographic data and test for sample selection bias

\begin{tabular}{llll}
\hline $\begin{array}{l}\text { Panel A: firm size } \\
\text { Number of employees }\end{array}$ & $\mathrm{N}$ & $\begin{array}{l}\text { Panel B: industry } \\
\text { Category }\end{array}$ & $\mathrm{N}$ \\
\hline $0-49$ & 2 & Construction & 11 \\
$50-99$ & 6 & Manufacturing & 30 \\
$100-249$ & 25 & Transportation, utilities & 3 \\
$250-499$ & 16 & Wholesale & 11 \\
$500-999$ & 7 & Retail & 3 \\
$1000-2499$ & 6 & Service & 8 \\
$>2500$ & 4 & & 66 \\
\hline Total & 66 & Total & \\
\hline
\end{tabular}

Panel C: comparison of constructs for early and late respondents

\begin{tabular}{llll}
\hline Construct & $\begin{array}{l}\text { Mean rank of construct } \\
\text { values } \\
\text { Early respondents }\end{array}$ & $\begin{array}{l}\text { Mean rank of construct } \\
\text { values } \\
\text { Late respondents }\end{array}$ & Mann-Whitney- $U$ Test \\
\hline Diagnostic use & $34.88(n=50)$ & $30.69(n=16)$ & $\begin{array}{l}Z=-0.681 \\
(p=0.496)\end{array}$ \\
Interactive use & $34.10(n=50)$ & $33.63(n=16)$ & $\begin{array}{l}Z=-0.450 \\
(p=0.653) \\
Z=-0.500 \\
(p=0.617)\end{array}$ \\
Cultural controls & $33.64(n=50)$ & $30.87(n=16)$ & \\
\hline
\end{tabular}

Panel D: representativeness of the sample

\begin{tabular}{|c|c|c|c|}
\hline Sales in Mill. EUR & Received questionnaires & & Expected questionnaires \\
\hline $20-39$ & 17 & & 25 \\
\hline 40-99 & 25 & & 23 \\
\hline $100-249$ & 15 & & 12 \\
\hline $250-1000$ & 9 & & 6 \\
\hline Total & & 66 & \\
\hline Chi-square & & 5.473 & \\
\hline df & & 3 & \\
\hline$p$-value & & 0.140 & \\
\hline
\end{tabular}

Panel E: nonresponse analysis for financial characteristics

\begin{tabular}{llll}
\hline Construct & $\begin{array}{l}\text { Respondents } \\
(n=66)\end{array}$ & $\begin{array}{l}\text { Nonrespondents } \\
(n=631)\end{array}$ & Mann-Whitney- $U$ Test \\
\hline ROA (in \%) & 4.95 & 5.61 & $\begin{array}{l}Z=-.0479 \\
(p=0.632)\end{array}$ \\
Profit margin (in \%) & 3.58 & 3.73 & $\begin{array}{l}Z=-.0174 \\
(p=0.862)\end{array}$ \\
Sales (in thous. EUR) & 133,695 & & $\begin{array}{l}Z=-2.344 \\
(p=0.019)\end{array}$ \\
\hline
\end{tabular}


study, we selected a two-stage approach. First, we conducted a fuzzy set qualitative comparative analysis (fs/QCA) to analyze how the MC package of the adoption of MA practices, the use of PMs, and the emphasis on cultural controls, as well as firm size, combine to achieve high (and low) firm performance in FBs. Second, we analyzed the cases included in the configurations (i.e., MC packages) identified by QCA. We explored additional information, including the: (i) intensity of price competition; (ii) intensity of quality competition; (iii) intensity of top management paying daily attention to information from underlying MA practices; (iv) intensity of top management's interpretation of information from underlying MA practices; and (v) dominating values of organizational culture to facilitate the interpretation of our results and to explain FB configurations.

QCA is a set-theoretic method that enables the investigation of complex configurational patterns (Ragin 2000, 2008; Schneider and Wagemann 2012). It "[...] assesses whether, or to what degree, a case [i.e., one specific FB] is a member of a set and then analyzes the intersection between sets" (Rihoux and Marx 2013, p. 168). In contrast to statistical methods that describe dependent and independent variables and their correlations, set-theoretic methods, such as QCA, analyze sets (i.e., conditions, such as operational MA practices or the interactive use of PMs) and set relations (i.e., combination of conditions) to explain an outcome (i.e., firm performance) (Schneider and Wagemann 2012; Thiem et al. 2016). We prefer QCA as a configurational approach over other methods discussed in configuration research (Gerdin and Greve 2004; Bedford and Sandelin 2015), such as cluster analysis, the profile deviation score approach, or moderated regression analysis. ${ }^{17}$ Regression analyses emphasize the average effects of variables and estimate a single solution for all cases (Fiss 2007; Woodside et al. 2012; Bedford and Sandelin 2015; Thiem et al. 2016). Cluster analysis and profile deviation scores identify different groups of firms but do not provide details about the interdependencies of variables, the quality of the segmentation, or the statistical tests to indicate significance (Fiss 2007; Bedford and Sandelin 2015). QCA overcomes these drawbacks and delivers metrics for coverage (similar to an R-squared value) and consistency (similar to a p-value) and reveals the importance of conditions (core, peripheral, or redundant) to achieve an outcome (Bedford et al. 2016). Furthermore, QCA determines the specific combination of conditions that leads to an outcome of interest (Fiss 2007).

Moreover, QCA explicitly addresses the core of configurational theory: asymmetry, conjunctional causation, and equifinality (Doty et al. 1993; Gresov and Drazin 1997; Fiss 2007; Schneider and Wagemann 2012; Bedford and Sandelin 2015). Equifinality indicates that various combinations of conditions (i.e., configurations) lead to the same outcome and implies that multiple paths coexist. The notion of conjunctural causation expresses that "[...] the effect of a single condition unfolds in combination with precisely specified other conditions" (Schneider and Wagemann 2012 , p. 324); the combination of conditions rather than one condition alone generates an outcome (Bedford and Sandelin 2015). In QCA, a configuration for the

\footnotetext{
17 The main differences between QCA and other methods of configurational research have been discussed in detail by Fiss (2007), Woodside (2013), and Bedford and Sandelin (2015).
} 
nonexistence of an outcome cannot be deduced from the configuration for the existence of that outcome (Schneider and Wagemann 2012). Therefore, separate analyses are required because conditions may asymmetrically influence an outcome. ${ }^{18}$

The identified combinations of conditions are construed in terms of sufficiency and necessity (Schneider and Wagemann, 2012). A sufficient condition X is defined as a subset of outcome $\mathrm{Y}(\mathrm{X} \rightarrow \mathrm{Y})$ and always occurs when outcome $\mathrm{Y}$ occurs, but outcome $\mathrm{Y}$ can also occur if condition $\mathrm{X}$ is absent $(\mathrm{X} \leq \mathrm{Y})$ (Schneider and Wagemann 2012). In contrast, a necessary condition $X$ is a superset of outcome $Y(X \leftarrow Y)$ and is present whenever outcome $\mathrm{Y}$ occurs, but outcome $\mathrm{Y}$ cannot be achieved if condition $\mathrm{X}$ is absent (X $\geq Y$ ) (Wagemann et al. 2016). Therefore, QCA is the most appropriate method for this study because it allows for the simultaneous analysis of the MC package (i.e., the adoption of different MA practices, use of PMs, and cultural controls in FBs) in conjunction with the contextual factor firm size. Therefore, we can analyze how the conditions of the MC package are combined within identified configurations (i.e., MC packages) and how they affect firm performance in FBs. Finally, for our setting of configurational FB research, equifinality, asymmetry, and conjunctural causation are considered relevant. We selected the software fs/ QCA Version 3.0 to analyze the data.

QCA follows three steps. First, the raw scores (i.e., the item values) for each variable are rescaled to fuzzy set membership scores between 0 (full nonmembership) and 1 (full membership), defining whether a case (i.e., an empirical observation) is in a set (i.e., a condition such as operational MA practices) or not. A crisp set is a special case of a fuzzy set that allows only dichotomous sets with membership scores of either 0 or 1 (Schneider and Wagemann 2012). However, if item values are on a continuous scale, then calibration with fuzzy sets is more suitable (Fiss 2007). A fuzzy set enables gradations of membership scores (e.g., scores $0 ; 0.2 ; 0.4 ; 0.6$; $0.8 ; 1.0)$.

The second step involves creating a truth table with all logically possible combinations of conditions as single rows ( $2^{\mathrm{k}}$ configurations for $\mathrm{k}$ number of conditions). Each case has a set membership score in all rows of the truth table, but the set membership score exceeds the qualitative anchor of 0.5 only in one row. Therefore, the point value of 0.5 describes the crossover point (midpoint) between full (1) and nonfull membership (0), which is "[...] the point of maximum ambiguity (i.e., fuzziness) in the assessment of whether a case is more in or out of a set" (Ragin 2008, p. 30). Calculation of set membership scores in a row follows the minimum scoring rule (Schneider and Wagemann 2012). ${ }^{19}$ Not all possible rows are empirically observed. Truth table rows without cases show limited diversity (Ragin 2000; Schneider and Wagemann 2012).

A configuration is sufficient for an outcome ( 1 in the outcome column of the truth table) if an assigned case in a specific configuration depicts the outcome of interest,

\footnotetext{
18 To address asymmetry in a separate analysis, we also investigate low-performing FBs.

19 For instance, the first FB has a set membership score of 0.6 in configuration $\mathrm{AB}$ (which implies one row of the truth table), which is the minimum of membership scores $\mathrm{A}(0.9)$ and $\mathrm{B}(0.6)(\mathrm{AB}=\min (\mathrm{A}$, $\mathrm{B})=\min (0.9,0.6)=0.6)($ cf. Ragin 2008, p. 129; Schneider and Wagemann 2012, p. 99).
} 
which in our study is high firm performance. A few cases in a configuration often represent the absence of the outcome rather than its presence; such rows are called contradictory rows and reduce the consistency of a configuration (Ragin 2000; Schneider and Wagemann 2012). To assess the sufficiency of the configuration with regard to the outcome, specification of the minimum frequency and consistency thresholds is required. Frequency refers to the number of empirical observations in a truth table row. A frequency threshold of one empirical observation for each row is usually defined for a sample between $\mathrm{N}=10$ and 100, as in our study (Schneider and Wagemann 2012). Consistency measures " [...] the degree to which the cases sharing a given condition or combination of conditions [...] agree in displaying the outcome [...]" (Ragin 2006, p. 292). We applied the recommended threshold of consistency for sufficient conditions of 0.8 (Schneider and Wagemann 2012).

The third step involves the application of the Quine-McCluskey algorithm based on Boolean algebra to minimize the complex solution term of the truth table (Ragin 2006). ${ }^{20}$ The result of the logical minimization reveals sufficient configurations that lead to the same outcome and the relative importance of identified core, peripheral, and redundant conditions that are essential to interpret the results (Fiss 2011). Fiss (2011, p. 398) defines core elements as "[...] those causal conditions for which the evidence indicates a strong causal relationship with the outcome of interest [...]," whereas peripheral conditions display "[...] [a weaker] evidence for a causal relationship with the outcome [...]." Redundant conditions are insignificant and have no impact on the outcome (Fiss 2011). Each configuration identified by the QCA approach can be assessed by parameters of fit (consistency and coverage). Coverage measures the empirical relevance of an alternative configuration (Ragin 2006) and is indicated for a specific configuration, the uniqueness of a specific configuration, and the entire solution term. The raw coverage of a configuration reveals the extent to which a configuration explains an outcome, whereas the unique coverage depicts the proportion of cases that are explained only by that configuration. The solution coverage indicates the percentage of the outcome set that is explained by all configurations (Schneider and Wagemann 2012).

\subsection{Calibration of variables}

We calibrated the conditions and the outcome variable for FBs as follows.

Adoption of MA practices. The two main categories of MA practices are operational and strategically oriented. In the questionnaire, individual MA practices were listed, and the participants assessed the instruments applied in their firms (possible

\footnotetext{
20 The minimization process of QCA results in three different solution terms. First, the complex solution is barely minimized without using simplifying assumptions. Second, the parsimonious solution depicts the most reduced solution term because all logical remainders are automatically considered. The conditions included in the parsimonious solution are called "prime implicants." Prime implicants cannot be further minimized. Third, between the two extremes, an intermediate solution is reduced by selected simplifying assumptions on the basis of the researcher's theoretical and empirical knowledge (see in detail Ragin 2008; Schneider and Wagemann 2012). We analyzed our data without simplifying assumptions. Therefore, Table 5 shows the complex solution.
} 
answers of yes or no). We discussed the membership of individual MA practices to the two main categories with experts. As operational MA practices, we included cost type and cost center accounting, standard calculations, calculations of actual costs, direct costing, and cash flow accounting/cash flow statement, whereas strategically oriented MA practices included forecasts for balance sheets and income statements, strategic and business planning, the Balanced Scorecard, risk management systems (e.g., risk inventory, assessment, and reporting), and environmental management systems. Using these raw data, we calibrated the operational and strategically oriented MA practices with the indirect method (Ragin 2008): full membership (1) in the set when the firm adopts all five MA practices, and full nonmembership (0) in the set when the firm does not adopt any MA practices. When a firm adopts one of the five potential MA practices, it is "mostly but not fully out" $(0.2)$, whereas the adoption of two practices indicates that the firm is "more out than in the target set" (0.4) (Ragin 2008, p. 96). Correspondingly, "more in than out in the target set" constitutes cases with three of the five practices (0.6), and "mostly but not fully in" constitutes cases with four of the five MA practices (0.8) (Ragin 2008, p. 95). This calibration enables consideration of various levels of adoption of operational and strategically oriented MA practices. Table 3 shows the descriptive statistics of the adoption of MA practices.

Use of PMs. To distinguish between the adoption of MA practices and the types of use, we measured diagnostic and interactive use as the use of a performance measurement system with PMs provided by operational and strategically oriented MA practices. The measures of diagnostic and interactive use are covered by eleven survey items using a five-point Likert scale from Henri (2006) based on the levers of control framework of Simons (1995). The empirical analyses (i.e., exploratory factor analysis and Cronbach's alpha) supported construct and content validity (see Table 2 and Table 3). Unreported validity and reliability criteria met their respective thresholds. In addition to Cronbach's alpha, Table 3 shows the descriptive statistics of the questionnaire items of diagnostic and interactive use.

A calibration based on the scale points is not appropriate because the median $(4.25)^{21}$ of diagnostic use indicates that almost all firms have a high degree of diagnostic use. Therefore, we followed the calibration of Bedford et al. (2016) and interpreted set membership in diagnostic use as either "very high" or "not very high" (Bedford et al. 2016, p. 17). The raw scores for diagnostic use for each FB were benchmarked against all of the sample scores for diagnostic use. If an FB has a raw score for diagnostic use in the 25th percentile, then the FB belongs to the set of "not very high" diagnostic use, whereas a raw score in the 75th percentile applies to FBs with a "very high" degree of diagnostic use. The median (4.25) is the crossover point. $^{22}$ The same procedure was conducted for interactive use (median: 3.43 ).

\footnotetext{
21 The median of the entire sample of 267 firms.

22 Some studies add a constant of 0.001 to all membership scores of 0.5 to prevent exclusion of cases from the analysis (Fiss 2011; Bedford et al. 2016). Wagemann et al. (2016) criticize this procedure and note that this should not become common practice. Therefore, we did not add or subtract a constant of 0.001 in our analysis.
} 


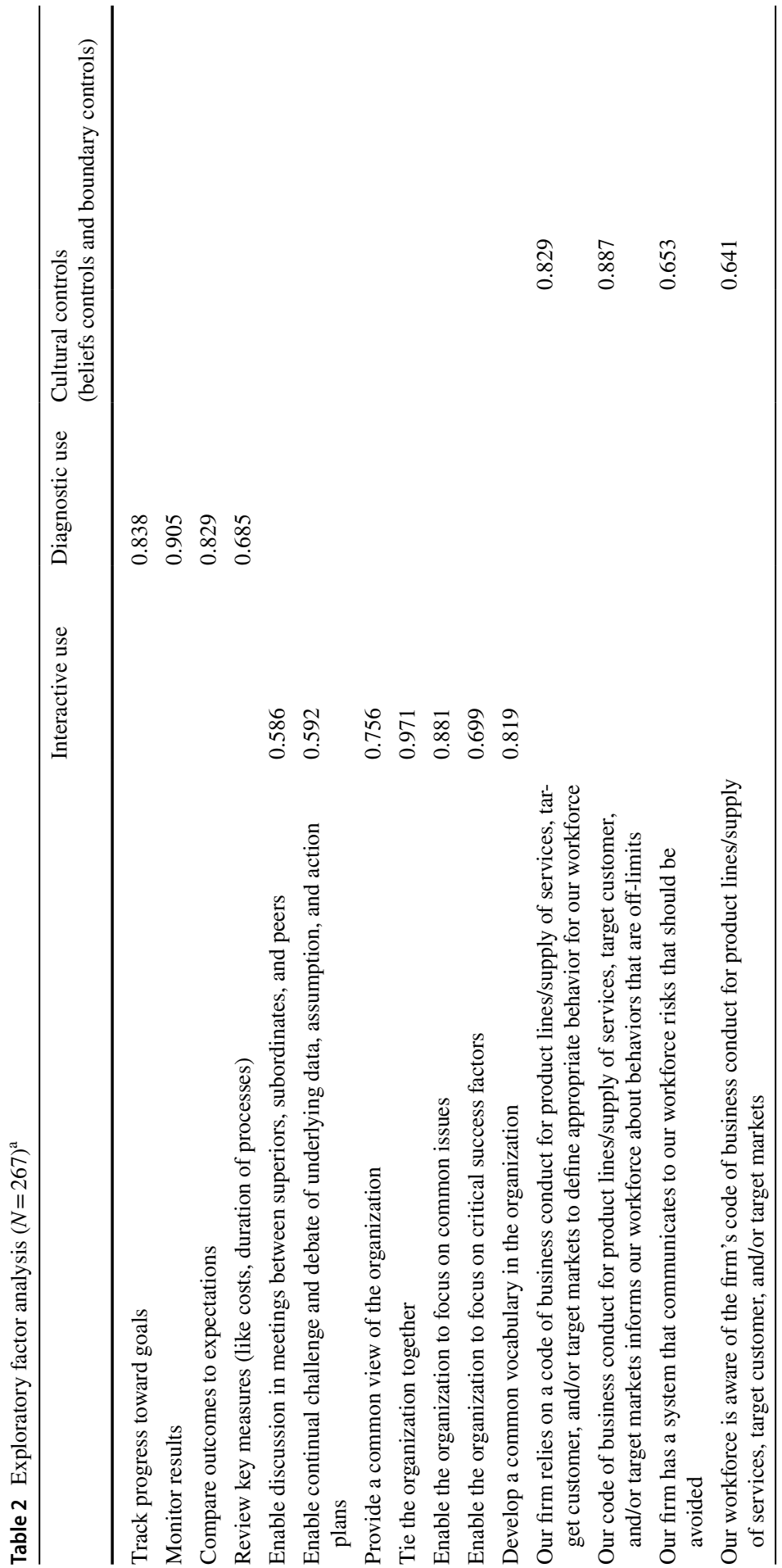




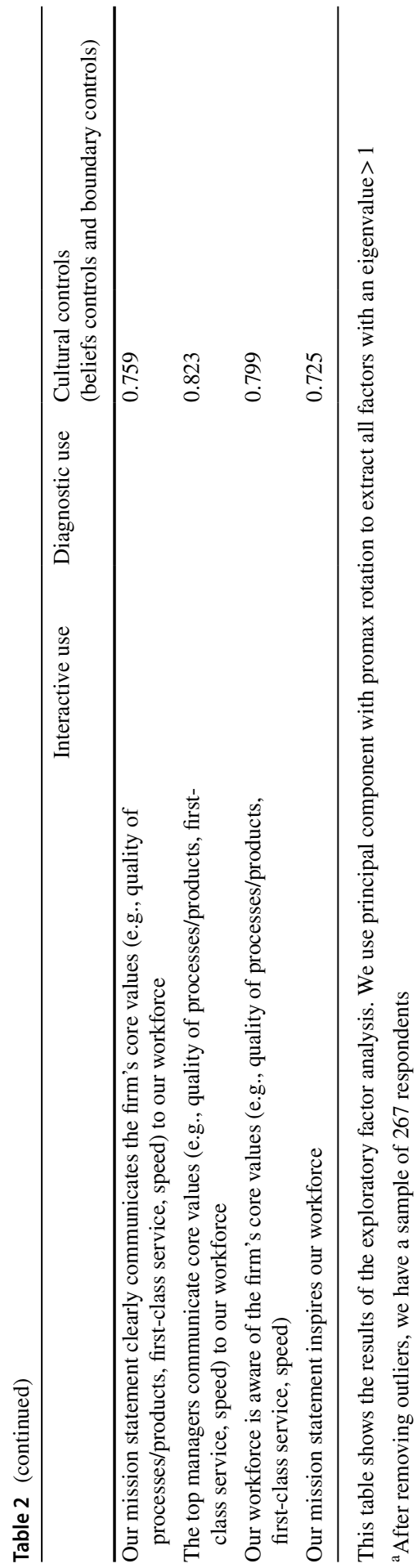




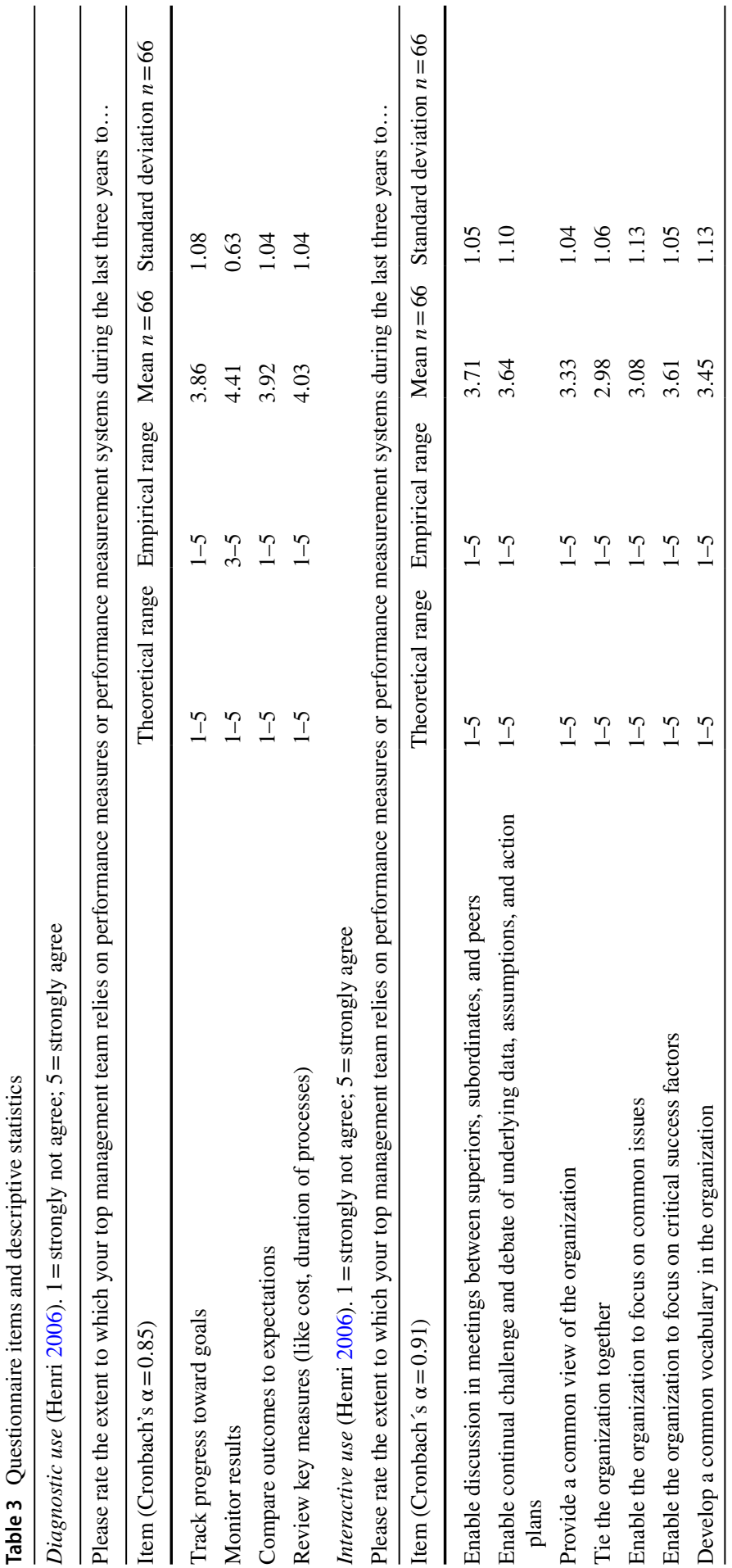




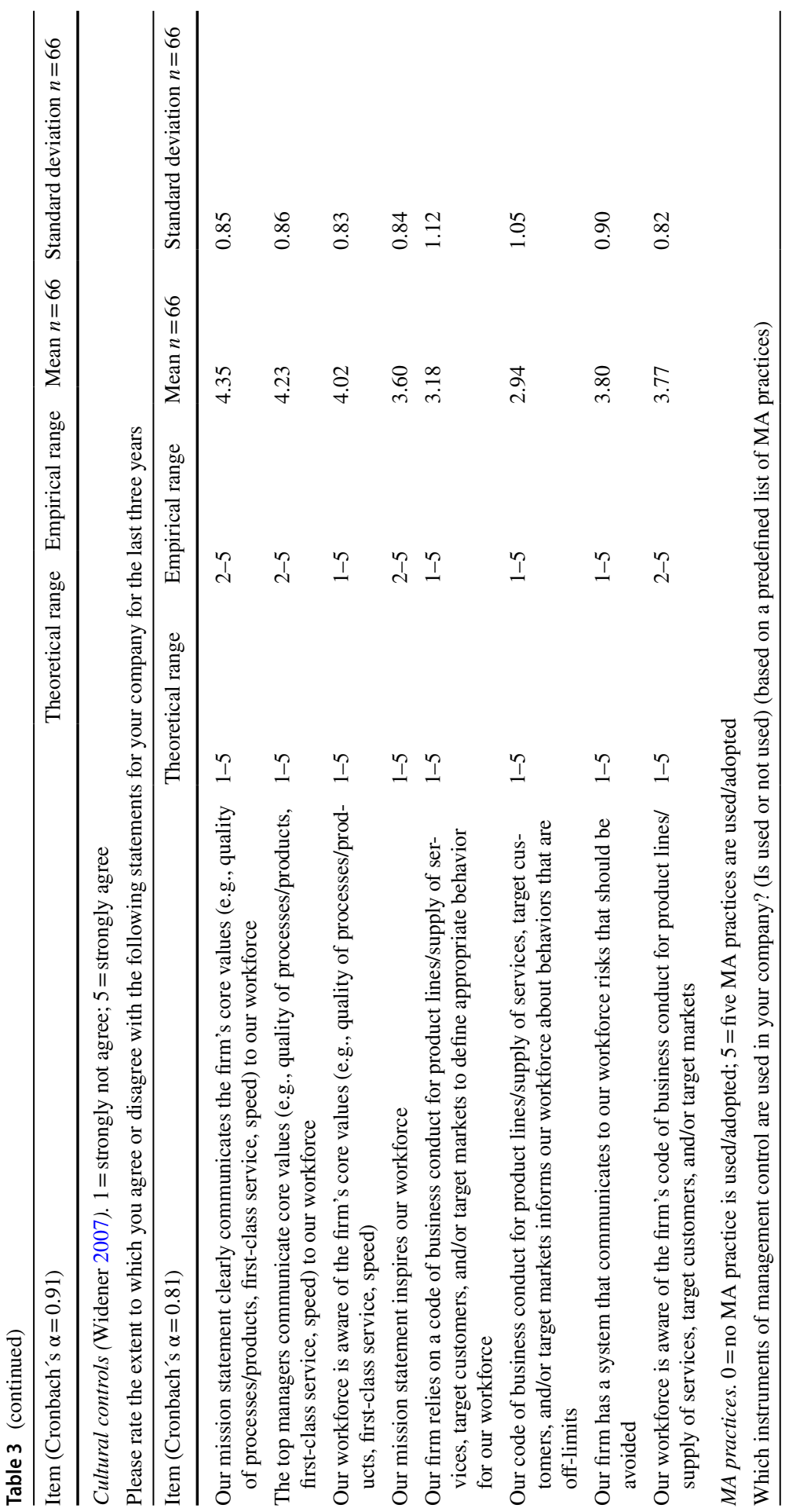




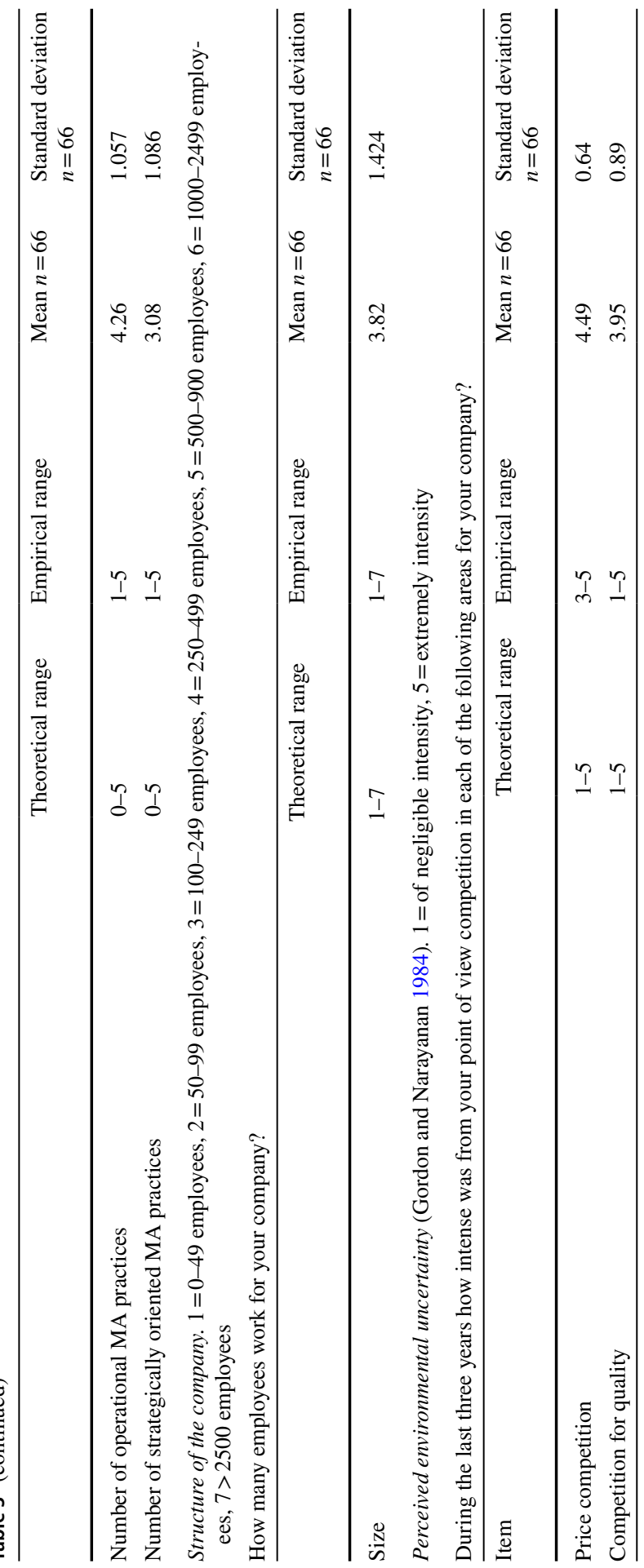




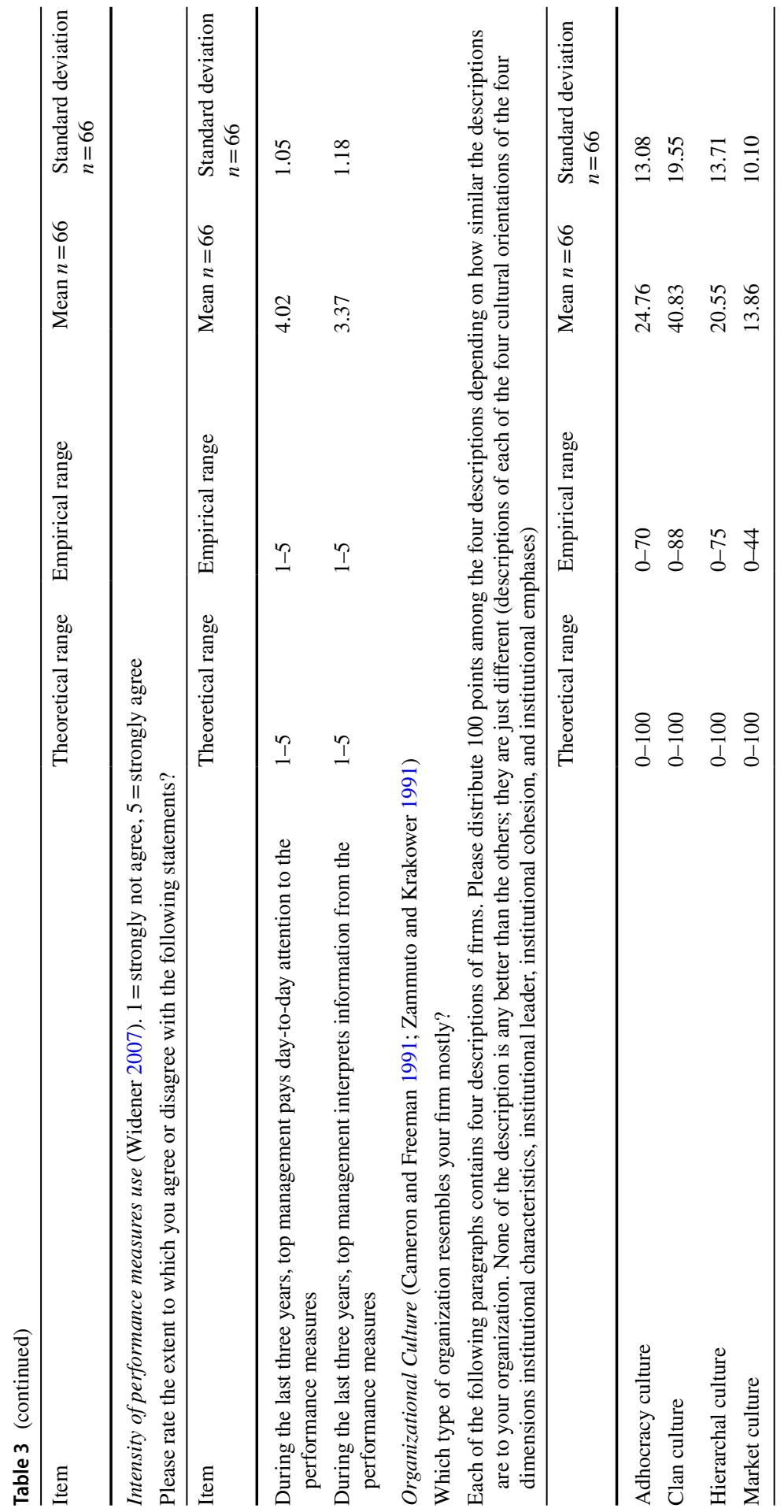


Cultural controls. To measure cultural controls, we used four questions that assessed the communication of areas that are off-limits to employees and four questions that assessed the communication of core values and the use of mission statements. All items were previously validated by Widener (2007). Furthermore, to support construct and content validity, we conducted an exploratory factor analysis (see Table 2). Unreported validity and reliability criteria met the respective thresholds. Table 3 depicts the descriptive statistics of the questionnaire items and Cronbach's alpha of the cultural controls. By aggregating these items (i.e., average scores of all eight items), we follow, on the one hand, prior MC theory in combining the values and norms that imply the way of behaving (Merchant and Van der Stede 2017) and, on the other hand, empirically validated procedures (Kleine and Weißenberger 2014; Goebel and Weißenberger 2017a, 2017b). This process allows for reducing the number of logically possible combinations of conditions ${ }^{23}$ and, thereby, avoids the problem of limited diversity.

To enable comparisons, cultural controls were calibrated using the same method as that for interactive and diagnostic uses. A calibration based on scale points is not appropriate because the median $(3.707)^{24}$ for cultural controls indicates that almost all firms strongly emphasize cultural controls. Therefore, we interpreted set membership in cultural controls as either "strong emphasis" or "no strong emphasis." The raw scores for cultural controls for each FB were benchmarked against all sample scores for cultural controls. If an FB has a raw score for cultural controls in the 25 th percentile, then the FB belongs to the set of "no strong emphasis" on cultural controls, whereas a raw score in the 75th percentile applies to FBs with a "strong emphasis" on cultural controls. The median (3.707) is the crossover point.

Firm size. Firm size was measured by the generally recommended proxy of number of employees (Hoque and James 2000; Chenhall 2003), which is frequently applied in FB research (Hiebl et al. 2013, 2015) because the number of employees drives complexity in FBs and, thus, determines the need for MA practices and MCs. We followed the classification of the European Union and calibrated firms with less than 250 employees as smaller FBs, which are fully out of the set of larger FBs, whereas FBs with at least 250 employees are fully in the set of larger FBs. Table 3 shows the descriptive statistics of firm size.

Return on assets. Our outcome of interest is firm performance. Following previous studies, we use ROA as a proxy (Fiss 2011; Dekker et al. 2015; Erkens and Van der Stede 2015) to ensure comparability and because profitability is one of the most frequently used firm performance measures (Pindado and Requejo 2015). We use archival data from the AMADEUS database to calculate ROA as the 2008 to 2010 mean of earnings before interest and taxes (EBIT) divided by total assets to avoid annual variations and to capture sustainable firm performance. For the calibration following Fiss (2011) and Erkens and Van der Stede (2015), we benchmarked the average ROA of a firm against an industry ROA, which was calculated from firms in the AMADEUS database within the same industry using double-digit NACE codes.

\footnotetext{
23 The recommendation is that the number of logically possible combinations of conditions should be smaller than the sample size (Schneider and Wagemann 2012).

24 The median of the entire sample of 267 firms.
} 
If an FB has a ROA in the 75th percentile of its industry, then the FB belongs to the set of high-performing firms, whereas an FB with a ROA in the 25th percentile is coded as a low-performing FB. The median is the crossover point.

Table 4 shows the correlation matrix and the square root of the average variance extracted (AVE) in the diagonal. The square root of AVE of each construct exceeds the respective correlation with any other construct, demonstrating adequate discriminant validity, according to Fornell and Larcker (1981).

\subsection{Additional variables}

In the second stage of our analysis, we considered additional variables to explain our results for the identified configurations (i.e., MC packages) of FBs. Further investigating the cases within the configurations is a major advantage of the QCA approach (Ragin 2008), allowing for deeper insight and understanding. "Amongst external factors, competition has been regarded as a key factor to explain the design and [adoption] of [MA practices and MCs]" (Amat et al. 1994, p. 118). To control for perceived environmental uncertainty, respondents were asked to rate the intensity of both price and quality competition for their firms over the last three years. We addressed validated instruments on a five-point Likert scale (with $1=$ "of negligible intensity" to 5= "extremely intense") developed by Gordon and Narayanan (1984). Furthermore, prior studies have shown that an association exists between the attention paid to PMs by top management and the intensity of the competition (Khandwalla 1972; Amat et al. 1994). Considering this factor, we also took into account the intensity over the last three years of the top management's: i) daily attention paid and ii) interpretation of information based on information from PMs. We used validated measures on a five-point Likert scale (with $1=$ "strongly not agree" to $5=$ "strongly agree") developed by Widener (2007) on the basis of the discussion in Simons (1995). The scoring of additional variables is based on the mean of fivepoint Likert scale scores, similar to Henri (2009): "very low" [1.0, 1.8] (interval of mean scores); "low" (1.8, 2.6]; "moderate" $(2.6,3.4]$; "high" $(3.4,4.2]$; and "very high" $(4.2,5.0]$.

Furthermore, we account for the type of organizational culture because, from a theoretical point of view, clan culture should be the most pronounced in FBs. We operationalized and measured the extent of organizational culture using the competing values framework on the basis of Cameron and Freeman (1991) and Zammuto and Krakower (1991). Respondents were asked to distribute 100 points among the four cultural types (i.e., hierarchy, clan, adhocracy, and market) for four questions that assessed their perceptions regarding their firm's character, leadership, cohesion, and emphases. The competing values framework crosses a flexibility/control axis with a people/organization axis to construct four types of cultures corresponding to each quadrant. Typically, firms cannot be classified clearly into one quadrant but rather have characteristics (i.e., competing values) from different quadrants by emphasizing one or two of them. Table 3 depicts the descriptive statistics of all additional variables. 


\section{Results}

\subsection{Results of QCA}

As previously mentioned, QCA enables the identification of necessary and sufficient conditions. Necessary conditions (e.g., operational MA practices) are present when the outcome (e.g., high firm performance) is present, but the outcome (e.g., high firm performance) cannot be achieved without this necessary condition (e.g., operational MA practices) (Wagemann et al. 2016), whereas sufficient conditions (e.g., operational MA practices) are present when the outcome (e.g., high firm performance) is present, but the outcome (e.g., high firm performance) can also occur when the condition (e.g., operational MA practices) is absent (Schneider and Wagemann 2012). Wagemann et al. (2016) recommend analyzing the necessary and sufficient conditions separately and the necessary conditions first. Therefore, before we analyzed the sufficient conditions, we conducted a test of necessity for each condition because the analysis of sufficiency does not permit conclusions regarding the necessary conditions. Following the recommendation by Skaaning (2011) to use a consistency value of at least 0.9 for necessary conditions, our analysis identified only high adoption of operational MA practices as a necessary condition for achieving high firm performance in FBs. However, the unreported XY plot identifies that 16 of 66 cases are located above the diagonal, implying that high adoption of operational MA practices in 16 cases is a sufficient (high adoption of operational MA practices is a subset of high firm performance; $\mathrm{X}<\mathrm{Y}$ ) and not a necessary condition. Therefore, operational MA practices are not a necessary condition.

Table 5 shows the results of the sufficient conditions for high-performing FBs and the additionally explored variables. We followed the notation of Ragin and Fiss (2008) and Fiss (2011) in which solid circles (•) refer to the presence of a condition, and circles with a cross $(\otimes)$ designate the absence of a condition. On the basis of our calibration, we interpreted our results according to high and low levels of adoption, (very) high and not (very) high degrees of PM use, and strong and not strong emphasis on cultural controls. Large circles represent core elements, and small circles depict peripheral elements. Blank spaces indicate that the condition is redundant for achieving the outcome. Our findings are described using information from both stages one and two of our analysis.

The analysis in stage one includes the MC package with the following six conditions: operational and strategically oriented MA practices, diagnostic and interactive use of PMs, cultural controls, and firm size. We find six configurations, or rather MC packages, sufficient to achieve high firm performance in FBs (see Table 5). These multiple paths reinforce the concept of equifinality and show that different combinations of our conditions simultaneously result in high firm performance. All six MC packages show high scores for overall solution consistency and coverage. The acceptable consistency value of 0.818 indicates that the detected MC packages are consistent and well supported by the data. Furthermore, coverage of 0.62 indicates that 62 percent of the outcome is explained by the six MC packages. 


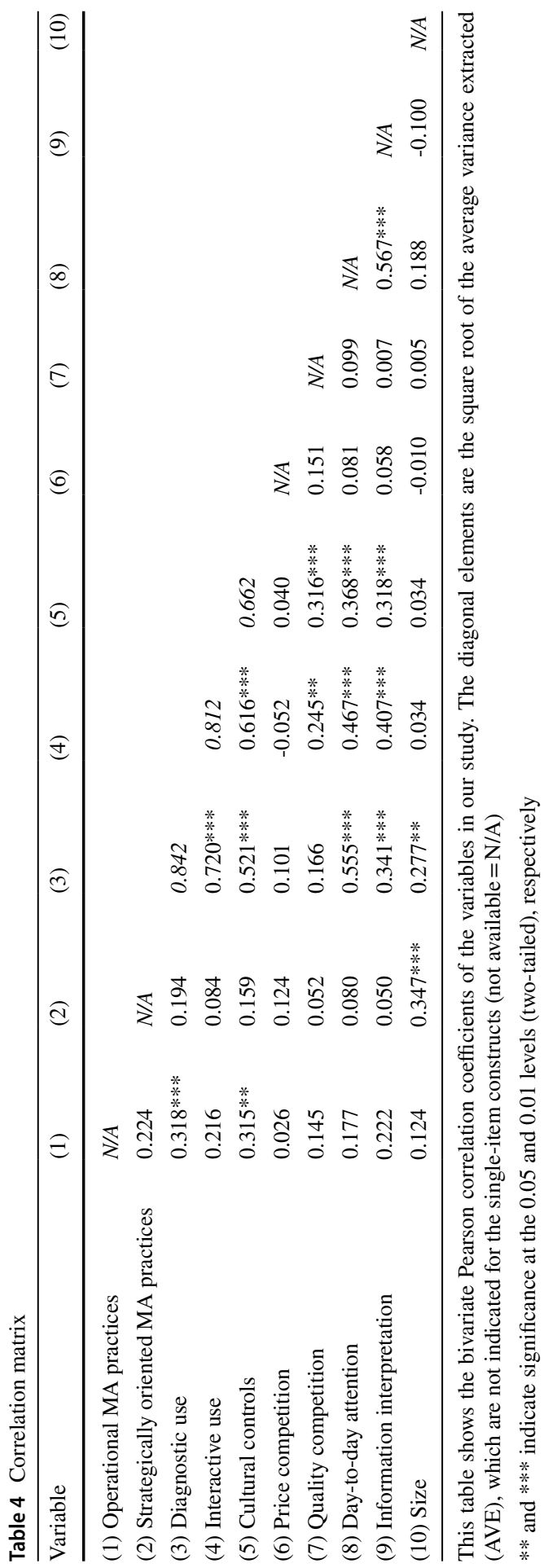




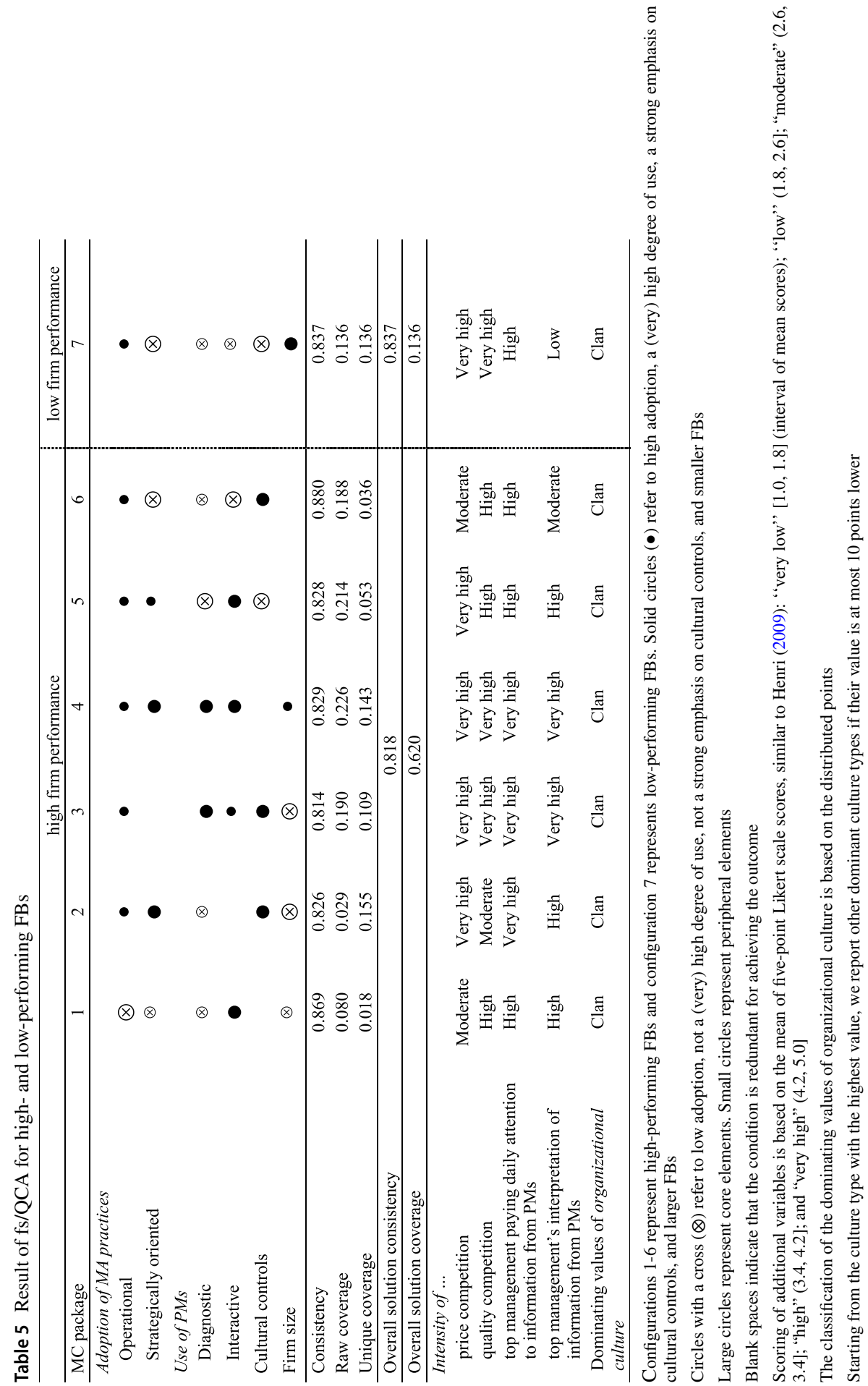


Our findings (MC packages 1 to 6 ) show that either a high degree of interactive use of PMs or a strong emphasis on cultural controls is always present and is a core element $(\bullet)$, implying that a strong relationship exists between interactive use of PMs and/or cultural controls and high firm performance in FBs. When exploring additional variables, all MC packages contain a strong emphasis on clan culture values (i.e., flexibility and people-oriented), which supports prior research (Duh et al. 2010). To foster values of cohesion, commitment, and loyalty, FBs might be more likely to control employees by cultural controls to communicate these values and undesired behaviors. Furthermore, using PMs interactively as communication channels stimulates discussions, empowers employees' commitment, and creates social ties through regular interactions. This finding is consistent with stewardship theory, which supports social relations and collaborative values.

The fs/QCA results for smaller FBs reveal three high-performing MC packages. MC packages 2 and 3 contain the core element of a strong emphasis on cultural controls and a smaller firm size. The presence of operational MA practices as a peripheral element is also observed in both MC packages. Variation occurs in the use of PMs and the adoption of strategically oriented MA practices. In MC package 3, in addition to the cultural controls, the core element of a very high degree of diagnostic use is combined with peripheral elements with a high degree of interactive use and the redundancy of strategically oriented MA practices. MC package 2 differs from MC package 3 because, on the one hand, the use of PMs is not very high for diagnostic use and is redundant for interactive use. On the other hand, an additional core element is the high adoption of strategically oriented MA practices. The pattern of the MC packages reveals that smaller FBs control the behavior of employees with cultural values and norms to achieve high firm performance but differ in the use of PMs because of the intensity of the competition. In MC package 3, with very high quality competition, the tracking and monitoring of critical success factors, such as quality, are essential as core elements to achieve high firm performance. This process also requires that top managers interpret collected information from PMs at a high level. Both MC packages 2 and 3 are situated in a very high price competition in which the top managers pay very high day-to-day attention to information from PMs. Our findings demonstrate that high adoption of operational and partially of strategically oriented MA practices can be combined with cultural controls to achieve high firm performance. MC package 1 shows that smaller FBs adopt fewer MA practices, which is consistent with prior research (e.g., García Pérez de Lema and Duréndez 2007; Feldbauer-Durstmüller et al. 2012; Speckbacher and Wentges 2012). In MC package 1, the core element of low adoption of operational MA practices and a high degree of interactive use is combined with peripheral elements of low adoption of strategically oriented MA practices and a not very high degree of diagnostic use, whereas cultural controls are redundant. This MC package allows for high firm performance by being highly interactive and using focused and limited information of PMs from fewer adopted MA practices as a communication tool, and by stimulating discussions and interaction with employees, paying high day-today attention to this information and interpreting information with high intensity by management. For this MC package, uncertainties derive from a moderate price but high quality competition. 
One MC package could be found for larger FBs. In MC package 4, the core elements-high adoption of strategically oriented MA practices and a very high degree of both diagnostic and interactive use of PMs - are combined with the peripheral element of high adoption of operational MA practices and the redundancy of cultural controls. Typically, larger firms emphasize more strategically oriented MA practices (Abdel-Kader and Luther 2008); thus, large FBs also converge in their adoption of MA practices to larger NFBs (e.g., Filbeck and Lee 2000; Feldbauer-Durstmüller et al. 2012). The PMs delivered by operational and strategically oriented MA practices are used to track and monitor success factors and stimulate discussions between management and employees driven by a very high price and a quality competitive situation. Additionally, managers pay very high day-to-day attention to information from PMs and interpret this information with very high intensity. The control of employee behavior through cultural values and norms is redundant. They may be present in the firm but are no longer sufficient to achieve high firm performance in these larger FBs.

Two MC packages are observed to be unrestricted by size. In MC package 5, the core element of a high degree of interactive use of PMs, a not very high degree of diagnostic use of PMs, and a not strong emphasis on cultural controls are combined with peripheral elements of a high level of both operational and strategically oriented MA practices. MC package 6 differs from 5 in that the core element of a strong emphasis on cultural controls and a not high degree of interactive use of PMs are reversed, whereas a not very high degree of diagnostic use of PMs is a peripheral element, and low adoption of strategically oriented MA practices becomes a core element. The differences in core elements point out that both are quite different configurations to achieve high firm performance. MC package 5 indicates rather interactive FBs, in which PMs from adopted MA practices, particularly strategically oriented MA practices with planning tools and risk management systems, are used as communication tools to stimulate dialogue between management and employees. In MC package 6, lower adoption of strategically oriented MA practices is combined with lower degree of use; thus, interactive use of PMs is not relevant for this package to achieve high firm performance. However, cultural controls are important and have a strong relationship with high firm performance. These results are supported by additional variables for the intensity of price competition and the intensity of top management's interpretation of information. The rather culturally control-driven FBs in MC package 6 face only moderate price competition and, thus, might not be forced to intensively interpret the information of MA practices, reflecting the not high degree of the use of PMs in these FBs.

After the QCA for high-performing FBs, we performed a separate analysis for low firm performance because MC packages for low-performing FBs cannot be deduced from the MC packages of high-performing FBs (Schneider and Wagemann 2012) because of potential asymmetry. Before analyzing sufficient conditions, we also conducted a test of necessity. Operational MA practices represent a consistency score greater than the recommended threshold (0.92), but the unreported XY plot again reveals six cases above the diagonal, implying that in six cases, the high adoption of operational MA practices is a sufficient condition (high adoption of operational MA 
practices is a subset of high firm performance; $\mathrm{X}<\mathrm{Y}$ ). Therefore, operational MA practices are not a necessary condition in low-performing MC packages (Schneider and Wagemann 2012). Table 5 shows one sufficient configuration for low-performing FBs (MC package 7) with a high overall solution consistency of 0.837 , indicating that the detected MC package is consistent and well supported by the data. However, the rather low coverage of 0.136 indicates that 13.6 percent of the outcome is explained by this MC package. Thus, for low performers, further combinations of MA practices and cultural controls exist but are inconsistent and contradict each other. Therefore, these combinations are below the consistency threshold and are not included in the minimization process. Thus, only one consistent MC package could ultimately be detected for low-performing FBs. In MC package 7, the core elements of the low adoption of strategically oriented MA practices, a not strong emphasis of cultural controls, and larger firm size are combined with the peripheral elements of the high adoption of operational MA practices and a not (very) high degree of both types of uses. This MC package is supplemented by a very high, intense price and quality competition in which top management shows high attention through focusing but only a low level of interpretation of PMs. This finding is generally consistent with Songini and Gnan (2015), indicating that simply adopting operational MA practices does not lead to high firm performance, especially under the condition of MC package 7-intense price and quality competition. Thus, FBs are advised to more intensively use the PMs provided by their MA practices.

These seven configurations resulting from fs/QCA do not reveal a logical contradiction $^{25}$ because the identified MC packages of high- and low-performing FBs are different, indicating asymmetry (Bedford and Sandelin 2015). Thus, we are able to show that the nonexistence of the elements of an MC package for a high-performing FB does not automatically result in low firm performance. For example, none of the negations of the MC packages 1 to 6 for high performance is identical to the MC package 7 for low performance.

\subsection{Robustness test}

We also investigated the MC packages for NFBs to identify differences between the configurations of FBs and NFBs. The analysis is based on a sample of 76 NFBs and considers the same set of MA practices, types of use, and cultural controls. The test of necessary conditions reveals operational MA practices with a consistency value greater than 0.95 . The unreported $\mathrm{XY}$ plot identifies eight of 76 cases above the diagonal $(\mathrm{X}<\mathrm{Y})$. Therefore, operational MA practices are not a necessary condition in high-performing MC packages for NFBs.

\footnotetext{
25 This argumentation is supported by the proportional reduction in the inconsistency (PRI) value, which indicates the degree to which a given combination of MA practices, types of use, and cultural controls is specifically a subset of the high firm performance outcome and not a subset of the low firm performance outcome and, thus, "[...] taking into account the simultaneous subset relation [...]" (Schneider and Wagemann 2012, p. 243). The PRI values of a consistent combination of MA practices, types of use, and cultural controls for high firm performance (low firm performance) are all greater than $0.61(0.59)$ and indicate that the combination of these MA practices and cultural controls should considered sufficient for high firm performance (low firm performance).
} 
Table 6 shows the results of sufficient conditions for high-performing NFBs and additional variables. The analysis reveals three ${ }^{26}$ sufficient MC packages for highperforming NFBs with an acceptable overall solution consistency value of 0.798 ; however, low coverage of 0.277 exists. The three MC packages are consistent, but only 27.7 percent of the outcome is explained by these MC packages. All MC packages of NFBs indicate high adoption of operational MA practices, a not strong emphasis on cultural controls, and a smaller firm size as core elements. Variation occurs in the use of PMs and the adoption of strategically oriented MA practices. NFBs use PMs to either a very high degree diagnostically (MC package A and B) or a high degree interactively (MC package $\mathrm{C}$ ). Thereby, one of the two types of use is always present and is a core element. The pattern of the MC packages reveals that smaller NFBs use their PMs more diagnostically to track and monitor critical success factors because managers are accountable for their decisions to the owners, reflecting a principal-agent problem that contraries to the steward perspective of FBs. Furthermore, MC package B shows high adoption of strategically oriented MA practices in an environment with high price and quality competition associated with high day-to-day attention and a high interpretation of PMs by management. MC package $\mathrm{C}$ is situated in a very high price and quality competition in which top managers pay only moderate attention to PMs and, thus, interpret this information on a low level. However, these NFBs are also high-performers through the adoption of operational MA practices and the use of PMs in an interactive manner. Uncertainties from the intensive competition are discussed in regular meetings between managers and employees. Thus, employees are encouraged to search for new opportunities. All MC packages show a mix of dominant values of organizational culture. In addition to clan cultures, which dominated FBs, smaller NFBs also pursue innovative values represented by adhocracy culture.

\section{Discussion and conclusion}

The purpose of our study was to expand the current understanding of how the adoption of operational and strategically oriented MA practices, the use of PMs, and the emphasis on cultural controls are combined in FBs (i.e., MC packages) while considering the competitive context in which these firms operate. Our results show that cultural controls and/or the interactive use of PMs are strongly related to high firm performance in FBs, thus confirming the assumption that

\footnotetext{
${ }^{26}$ We had to choose a prime implicant because the minimization process results in two prime implicants that cover one configuration, that is, one prime implicant is logically redundant (Schneider and Wagemann 2012). We decided to use the prime implicant with high adoption of operational MA practices and PMs that are used very high diagnostically that are not used high interactively with a strong emphasis on cultural controls in smaller NFBs. This decision is based on the theoretical and empirical knowledge that NFBs are confronted with principal-agent problems. Therefore, the tracking and monitoring of critical success factors, which are predefined, is essential to verifying that employed managers behave in the interest of the owner and, thus, in line with the organizational goals.
} 


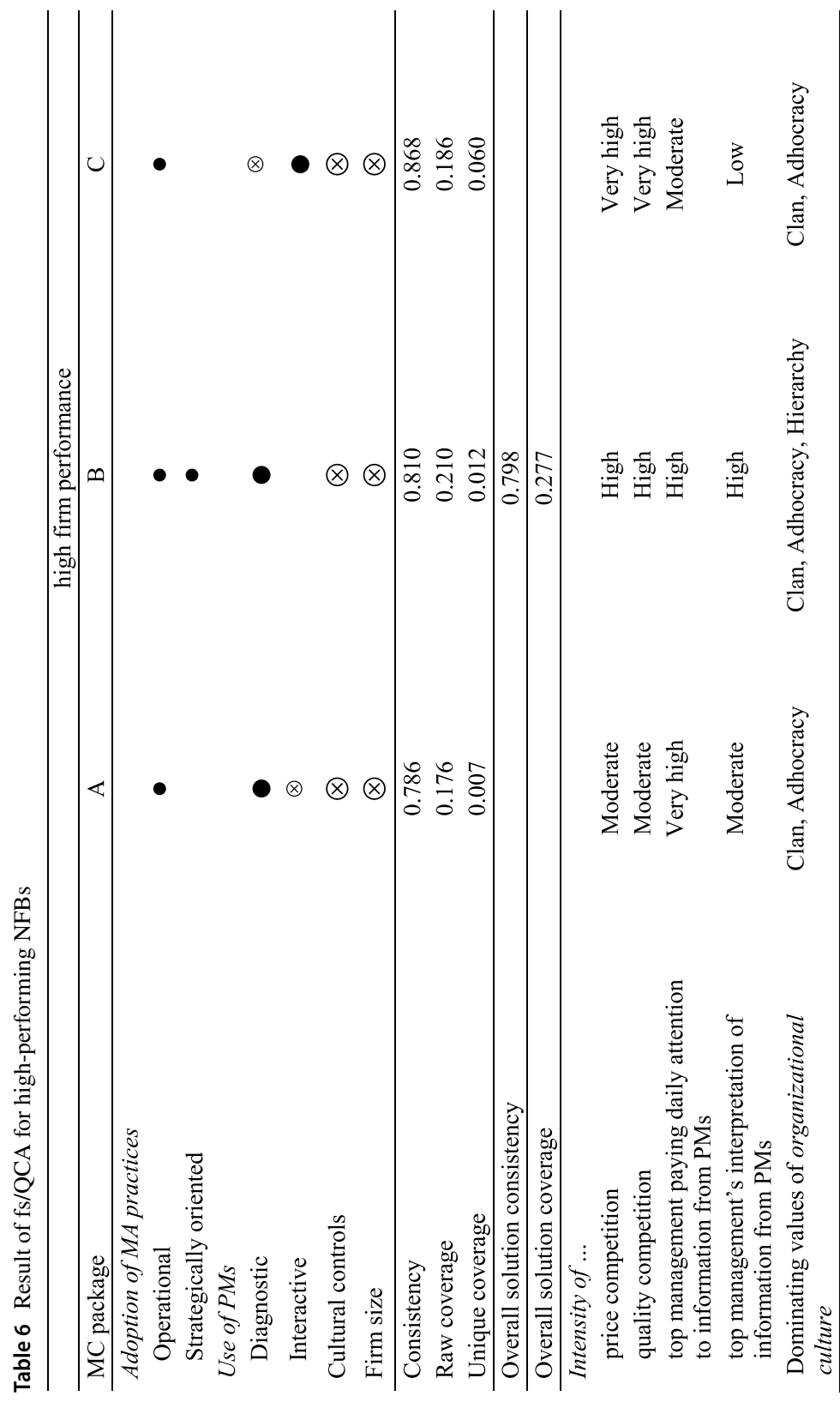

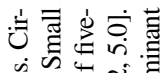

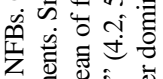

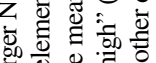

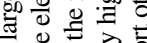

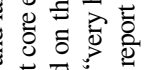
苞苾

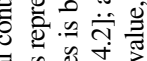
政

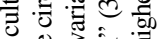

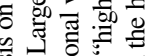

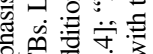
鱼政 足额

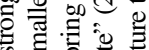
的语 s. ज 0 to 항 है

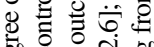

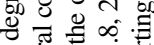

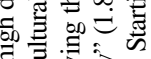

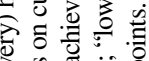
远. o

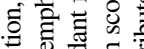

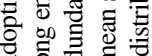
함 然

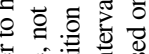

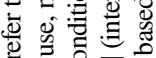
t - \&

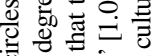

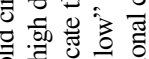
के 글

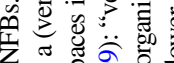
풍 on 하월

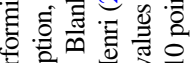

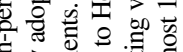

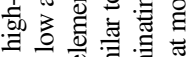

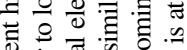
政, 哥 는

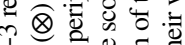

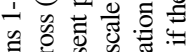
of o

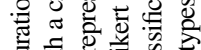

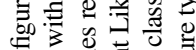

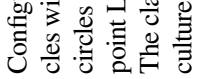


cultural controls are effective and relevant in firms with social relations and strong ties, such as FBs (Dekker et al. 2015; Helsen et al. 2017; Merchant and Van der Stede 2017). Cultural controls define the social conventions in FBs (Merchant and Van der Stede 2017), which include clan cultural values such as cohesion and commitment (Duh et al. 2010; Cameron and Quinn 2011). In addition to cultural controls, the interactive use of PMs is also relevant in high-performing FBs, supporting the general argumentation that the use of PMs is important to achieving high firm performance and that stewardship behavior-induced commitment in FBs fosters interactions with employees by discussing information in face-to-face meetings (e.g., Bourne et al. 2005; Henri 2006; Songini and Gnan 2015). Our results, which are consistent with stewardship behavior, emphasize the importance of shared values and norms and interactions between members of FBs as a way to achieve firms' goals and eventually high firm performance (Dyer 2006).

Our study also sheds light on the adoption levels of MA practices in FBs. By analyzing a wider MC package, our study reveals that operational and strategically oriented MA practices in combination with cultural controls and/or interactive use of PMs can also be highly adopted in FBs. In particular, we confirm previous findings (see MC package 1) that smaller FBs adopt fewer MA practices (e.g., Feldbauer-Durstmüller et al. 2012; Speckbacher and Wentges 2012) but combine them with a high level of knowledge sharing in face-to-face meetings (Pittino et al. 2018). However, we also find two additional MC packages for smaller FBs with high adoption of MA practices (see MC packages 2 and 3). Thereby, the intensity of competition is a well-known, crucial factor in explaining the configuration of MC packages (Amat et al. 1994; Songini et al. 2018). General MA and MC research has found an increase in the adoption of MA practices, the use of PMs, and emphasis on MCs with the intensity of competition (Khandwalla 1972). Our results confirm these previous findings for FBs in a highly intensive price and quality competition. PMs are diagnostically and interactively used with a very high intensity of attention and interpretation of information from PMs by the top management (see MC packages 3 and 4). Smaller FBs are potentially more heterogeneous than larger FBs because they have far fewer MA practices than large FBs and, thus, focus only on the collection and use of certain information that they need depending on their competitive situation (see MC packages 1 and 6). Furthermore, we confirm that FBs in very intense competition achieve only low firm performance when they collect and use their PMs on a low level and weakly emphasize cultural controls (see MC package 7). Beyond the previous results of the FB literature, which mainly investigated family involvement, we can also highlight the intensity of the competition as a factor that influences the configuration of MC packages. Moreover, by considering the industry data despite a heterogeneous distribution of the responding firms (see Panel A Table 1), ${ }^{27}$ we

\footnotetext{
27 To draw conclusions regarding the industry, the previous six industry sectors were combined into two sectors. Manufacturing consists of construction and manufacturing. Service consists of transportation, wholesale, retail, and service.
} 
find that MC packages 6 and 7 consist only of manufacturing firms, whereas MC packages 1 to 5 do not reflect a clear distribution of manufacturing and service firms. This additional consideration shows that, for the low performing configuration type of industry-here, manufacturing firms - are relevant.

Furthermore, our study shows that smaller FBs and NFBs vary in the adoption level of MA practices, use of PMs, and emphasis on cultural controls. In particular, NFBs do not strongly emphasize cultural controls and diagnostically use their PMs to a very high extent (see MC packages A and B). This finding is consistent with Acquaah (2013, p. 144), who argues that "[...] diagnostic controls may be the forte of NFBs [...]". Considering stewardship theory, firms with strong commitment and mutual trust reduce the diagnostic use of PMs. However, in NFBs, problems arise because of a lack of alignment between the goals of the principals and agents. A better alignment of the goals of the principals and agents can be reached through agent-based governance, such as monitoring systems. According to agency theory, this action results in a more diagnostically driven use of PMs. Thus, the detected MC packages of FBs are not applicable to small and medium-sized firms in general, especially NFBs.

Our findings expand research on MA and MC in FBs in a number of ways. First, our findings show that not all MA practices observed to be or not to be associated individually with firm performance (e.g., Daily and Dollinger 1992; Speckbacher and Wentges 2012; Dekker et al. 2015) are necessarily relevant for achieving high firm performance when examined as part of MC packages (referring to conjunctional causation). Therefore, our study is the first attempt to identify MC packages that provide a more fine-grained understanding and add a classification scheme describing the configuration of different MA practices and cultural controls in FBs. Furthermore, the applied fs/QCA method provides information on the relevance of the adoption of MA practices and the use of PMs and cultural controls within a package by distinguishing among the redundant, peripheral, and core elements. Other methods, such as profile deviation and cluster analysis, which are commonly used to investigate MA practices and MCs in combination (e.g., Moores and Yuen 2001; Bedford and Malmi 2015; Kruis et al. 2016), provide only limited insights into the inner functioning of MC configurations. Our results confirm that the interactive use of PMs and/or cultural controls are core elements in each MC package and, thus, are more crucial success factors in FBs, which is supported by stewardship theory.

Second, our study presents empirical evidence for the existence of the equifinality of MC packages (Erkens and Van der Stede 2015; Bedford et al. 2016). Research based on contingency theory has often ignored the possibility of several viable responses to certain contingencies (Dent 1990; Fisher 1998) and instead has assumed a direct relationship between MA practices and/or MCs and context. However, our results do not mean that conventional contingency analyses are invalid because most of the MA practices within high-performing MC packages observed in our study are consistent with prior research (e.g., Speckbacher and Wentges 2012; Acquaah 2013). However, we identify six high-performing MC packages of FBs that are equally effective. In contrast to, for example, using regression analysis with interaction terms for $\mathrm{MC}$ configuration research, QCA 
allows for finding such equifinal configurations. Our findings show that FBs differ from one another not only as the previous literature has shown in terms of the composition of the board and management (e.g., Garcia-Castro and Aguilera 2014; Samara et al. 2017; Samara and Berbegal-Mirabent 2018) but also in terms of the configurations of MA practices and cultural controls. Thus, we illustrate that FBs apply a wide variety of control combinations, and we contribute to filling the knowledge gap regarding FB heterogeneity.

Third, our study refines the previous literature (e.g., Anderson and Reeb 2003; Dyer 2006) that addresses firm performance in FBs by also specifically examining low-performing FBs. Thus, we contribute to the discussion of asymmetry (Bedford and Sandelin 2015). Our findings show that MC packages are not logically contradictory because the MC packages of a low-performing FB are not combinations of the opposite characteristics of the MC packages of high-performing FBs, which indicates asymmetry.

Overall, our study emphasizes the need to investigate a large MC package in an FB setting and expands the literature by exploring equifinal combinations of MA practices and cultural controls in FBs, thus, responding to the calls of Helsen et al. (2017) and Songini et al. (2018). In summary, this study has theoretical implications for FB research. The identified and refined MC packages expand scholars' interpretative scope regarding both high- and low-performing FBs and allow for practical comparisons across FBs in terms of the adoption of MA practices, the use of PMs, cultural controls, firm size, and additional context variables, such as the intensity of competition. Our study demonstrates that the narrow focus on individual MA practices is not sufficient because it neglects interrelations with other MA practices and cultural controls. In particular, cultural controls and/or the interactive use of PMs are crucial factors for successful FBs. Furthermore, the applied research methodology of QCA allows for the identification of equifinal and asymmetrical configurations (MC packages) and, thus, offers a new way to analyze FBs.

In addition to the theoretical implications, our findings have implications for practitioners. This study shows that MA practices alone are not sufficient for achieving high firm performance; instead, a combination of the adoption of MA practices, use of PMs, and cultural controls is required. If management fails to emphasize the use of PMs or shared values and beliefs and communicate desired behavior, the FB cannot be successfully controlled. Furthermore, our study provides evidence that more than one way can be used to control an FB successfully. Therefore, an FB should identify the configuration to which it best fits. The first step in this process is the evaluation of its competitive environment. Next, FBs have equifinal managerial choices to select a suitable MC package (e.g., for tough price and quality competition, MC packages 3 to 5, and for moderate price and high quality competition, MC packages 1 or 6 ).

Our exploratory study represents a first step in identifying MC packages in FBs and can provide a basis for future research. For example, scholars could refine our MC packages in terms of the professionalization stages of FBs (Dekker et al. 2013) or in terms of the impacts of successors. Furthermore, future research could consider additional social MCs, such as personnel controls or action controls (Kleine and Weißenberger 2014; Goebel and Weißenberger 2017a, 2017b; Merchant and 
Van der Stede 2017), which might have systematic associations with the MCs considered in this study but that have not been regarded thus far in FB research. Moreover, previous research shows that diagnostic and interactive use can be complements (e.g., Henri 2006). However, "QCA does not specify whether attributes are interdependent [e.g., complements] [...]" (Bedford and Sandelin 2015, p. 22). However, the identified configurations of QCA may be used in future studies to inspire the investigation of complementary effects. ${ }^{28}$

Despite the contributions to theory and practice, this study is not devoid of limitations. The results and evidence are derived from a sample of German firms. Although the representation of FBs in Germany is similar to that in other European countries (IFERA 2003), further studies should be conducted to assess the generalizability of our results to different national settings. We are aware that the explored MC packages can vary across countries based on national cultures. Another limitation of our study is that the definition of FBs is based on ownership only. We do not consider the degree of family involvement (measured by FIBER or F-PEC). Our study examines the MC package of FBs from an external perspective (e.g., driven by contextual factors, such as competition). However, how the degree of family involvement is associated with the MC packages would be interesting to determine. Furthermore, this study examines control configurations regarding financial firm performance. Therefore, the association between FB configurations and nonfinancial goals could also be analyzed because nonfinancial issues (e.g., environmental and social performance, quality of products or services, and MC effectiveness) are also important. Another limitation is that we rely on more formal than informal parts of cultural controls. Only items two and three cover more informal aspects of cultural controls (see Table 3), although the examples of core values given in these items highlight rather technical aspects (e.g., quality of processes/products, first-class service, speed). Because informal parts of cultural controls have special significance for FBs, this might limit the results of our study. For future research to clearly differentiate between formal and informal cultural controls by investigating whether a difference exists between these two expressions in FBs would be interesting. A further limitation is the reliance on survey data from the subjective assessments of a member of the top management team. While considerable effort was exerted for the survey development, pretests, and assessment of construct validity, our measures might still be affected by noise. In addition, although several tests suggest (except for the comparison of sales) that our study might not significantly suffer from nonresponse bias, this possibility cannot be completely excluded. Finally, although our findings illustrate several ways to achieve high firm performance in a given context,

\footnotetext{
${ }^{28}$ However, some QCA studies (e.g., Misangyi and Acharya 2014) examine substitutes and complements. Misangyi and Acharya (2014) used an analysis of sufficient conditions to combine two conditions as a complement pair via an "and" operation that uses the minimum value and a substitute pair via an "or" operation that uses the maximum value. Each pair was examined separately in a specified model. Following the procedure described by Misangyi and Acharya (2014), we conducted an additional analysis of complements and substitutes. The results suggest that diagnostic use and interactive use as well as interactive use and cultural controls operate as complements because of empirical relevance (i.e., coverages exceed the coverage of the base model: diagnostic-interactive: 0.68 ; interactive-cultural: 0.72 ; base model: 0.62) (Misangyi and Acharya 2014).
} 
they do not imply that FBs "[...] have unrestricted agency in selecting the [MA practices and MCs] that constitute [a high firm performance leading] MC package or that these choices are without causal antecedents" (Bedford et al. 2016, p. 23).

Despite these limitations, this study expands the MA and MC research by identifying seven MC packages for FBs, examining how and why MA practices, types of use, and cultural controls combine. Therefore, we can clearly answer our research question by identifying consistent and equifinal configurations of MA practices and cultural controls for high-performing FBs (e.g., different MC packages). Therefore, we expand the current understanding of the choice and consequences of combinations of MA practices and cultural controls in the competitive context of FBs. Finally, our results show that a strong emphasis on interactive use of PMs and/or cultural controls is crucial to successfully controlling an FB.

Acknowledgements We appreciate the constructive comments and recommendations of the department editor, Christian Hofmann, and of two anonymous reviewers. We are thankful for helpful comments of the participants of the 14th Annual Conference for Management Accounting Research in Vallendar, Germany (2017) and of the 9th EIASM Conference on Performance Measurement and Management Control in Nice, France (2017). This paper uses a subsample of raw data previously collected by the third author, Thomas W. Guenther, and by Anja Heinicke. We acknowledge the participation of Anja Heinicke in collecting the raw data for this paper.

Funding Open Access funding provided by Projekt DEAL.

Open Access This article is licensed under a Creative Commons Attribution 4.0 International License, which permits use, sharing, adaptation, distribution and reproduction in any medium or format, as long as you give appropriate credit to the original author(s) and the source, provide a link to the Creative Commons licence, and indicate if changes were made. The images or other third party material in this article are included in the article's Creative Commons licence, unless indicated otherwise in a credit line to the material. If material is not included in the article's Creative Commons licence and your intended use is not permitted by statutory regulation or exceeds the permitted use, you will need to obtain permission directly from the copyright holder. To view a copy of this licence, visit http://creativecommons.org/licen ses/by/4.0/.

\section{References}

Abdel-Kader M, Luther R (2008) The impact of firm characteristics on management accounting practices: a UK-based empirical analysis. Br Acc Rev 40:2-27. https://doi.org/10.1016/j.bar.2007.11.003

Acquaah M (2013) Management control systems, business strategy and performance: a comparative analysis of family and non-family businesses in a transition economy in sub-Saharan Africa. J Fam Bus Strat 4:131-146. https://doi.org/10.1016/j.jfbs.2013.03.002

Alvesson M, Kärreman D (2004) Interfaces of control. Technocratic and socio-ideological control in a global management consultancy firm. Acc Organ Soc 29:423-444. https://doi.org/10.1016/S0361 $-3682(03) 00034-5$

Amat J, Carmona S, Roberts H (1994) Context and change in management accounting systems: a Spanish case study. Manag Acc Res 5:107-122. https://doi.org/10.1006/mare.1994.1008

Anderson RC, Reeb DM (2003) Founding-family ownership and firm performance: evidence from the S\&P 500. J Financ 58:1301-1328. https://doi.org/10.1111/1540-6261.00567

Anthony RN, Govindarajan V (2007) Management control systems. McGraw-Hill, Boston

Armstrong JS, Overton TS (1977) Estimating nonresponse bias in mail surveys. J Mark Res 14:396-402. https://doi.org/10.1177/002224377701400320

Barsade SG (2002) The ripple effect: emotional contagion and its influence on group behavior. Adm Sci Q 47:644-675. https://doi.org/10.2307/3094912 
Bedford DS, Malmi T (2015) Configurations of control: an exploratory analysis. Manag Acc Res 27:2-26. https://doi.org/10.1016/j.mar.2015.04.002

Bedford DS, Sandelin M (2015) Investigating management control configurations using qualitative comparative analysis: an overview and guidelines for application. J Manag Control 26:5-26. https://doi.org/10.1007/s00187-015-0204-3

Bedford DS, Malmi T, Sandelin M (2016) Management control effectiveness and strategy: an empirical analysis of packages and systems. Acc Organ Soc 51:12-28. https://doi.org/10.1016/j. aos.2016.04.002

Blumentritt T (2006) The relationship between boards and planning in family businesses. Fam Bus Rev 19:65-72. https://doi.org/10.1111/j.1741-6248.2006.00062.x

Bourne M, Kennerley M, Franco-Santos M (2005) Managing through measures: a study of impact on performance. J Manuf Technol Manag 16:373-395. https://doi.org/10.1108/174103805105944 80

Cameron KS, Freeman SJ (1991) Cultural congruence, strength, and type: relationships to effectiveness. Res Organ Change Dev 5:23-58

Cameron K, Quinn RE (2011) Diagnosing and changing organizational culture: based on the competing values framework. Jossey-Bass Publishing, San Francisco

Chenhall RH (2003) Management control systems design within its organizational context: findings from contingency-based research and directions for the future. Acc Organ Soc 28:127-168. https://doi.org/10.1016/S0361-3682(01)00027-7

Child J (1972) Organisational structure, environment and performance: the role of strategic choice. Sociology 6:1-22. https://doi.org/10.1177/003803857200600101

Chow CW, Shields MD, Chan YK (1991) The effects of management controls and national culture on manufacturing performance: an experimental investigation. Acc Organ Soc 16:209-226. https:// doi.org/10.1016/0361-3682(91)90001-U

Corbetta G, Salvato C (2004) Self-serving or self-actualizing? Models of man and agency costs in different types of family firms: a commentary on "comparing the agency costs of family and nonfamily firms: conceptual issues and exploratory evidence”. Entrep Theory Pract 28:355-362. https://doi.org/10.1111/j.1540-6520.2004.00050.x

Cunningham J, Seaman C, McGuire D (2017) Perceptions of knowledge sharing among small family firm leaders: a structural equation model. Fam Bus Rev 30:160-181. https://doi. org/10.1177/0894486516682667

Daily CM, Dollinger MJ (1992) An empirical examination of ownership structure in family and professionally managed firms. Fam Bus Rev 5:117-136. https://doi.org/10.111 1/j.1741-6248.1992.00117.x

Davis JH, Schoorman FD, Donaldson L (1997) Toward a stewardship theory of management. Acad Manag Rev 22:20-47. https://doi.org/10.5465/amr.1997.9707180258

Davis JH, Allen MR, Hayes HD (2010) Is blood thicker than water? A study of stewardship perceptions in family business. Entrep Theory Pract 34:1093-1116. https://doi.org/10.111 1/j.1540-6520.2010.00415.x

de García Pérez Lema G, Duréndez A (2007) Managerial behaviour of small and medium-sized family businesses: an empirical study. Int J Entrep Behav Res 13:151-172. https://doi. org/10.1108/13552550710751030

Dekker J, Lybaert N, Steijvers T, Depaire B, Mercken R (2013) Family firm types based on the professionalization construct: exploratory research. Fam Bus Rev 26:81-99. https://doi. org/10.1177/0894486512445614

Dekker J, Lybaert N, Steijvers T, Depaire B (2015) The effect of family business professionalization as a multidimensional construct on firm performance. J Small Bus Manag 53:516-538. https:// doi.org/10.1111/jsbm.12082

Denison D, Lief C, Ward JL (2004) Culture in family-owned enterprises: recognizing and leveraging unique strengths. Fam Bus Rev 17:61-70. https://doi.org/10.1111/j.1741-6248.2004.00004.x

Dent JF (1990) Strategy, organization and control: some possibilities for accounting research. Acc Organ Soc 15:3-25. https://doi.org/10.1016/0361-3682(90)90010-R

Doty DH, Glick WH, Huber GP (1993) Fit, equifinality, and organizational effectiveness: a test of two configurational theories. Acad Manag J 36:1196-1250. https://doi.org/10.5465/256810

Drazin R, Van de Ven AH (1985) Alternative forms of fit in contingency theory. Adm Sci Q. https:// doi.org/10.2307/2392695 
Duh M, Belak J, Milfelner B (2010) Core values, culture and ethical climate as constitutional elements of ethical behaviour: exploring differences between family and non-family enterprises. J Bus Ethics 97:473-489. https://doi.org/10.1007/s10551-010-0519-9

Dyer WG (1988) Culture and continuity in family firms. Fam Bus Rev 1:37-50. https://doi.org/10.111 1/j.1741-6248.1988.00037.x

Dyer WG (2006) Examining the "family effect" on firm performance. Fam Bus Rev 19:253-273. https:// doi.org/10.1111/j.1741-6248.2006.00074.x

Eddleston KA, Kellermanns FW (2007) Destructive and productive family relationships: a stewardship theory perspective. J Bus Ventur 22:545-565. https://doi.org/10.1016/j.jbusvent.2006.06.004

Eddleston KA, Kellermanns FW, Sarathy R (2008) Resource configuration in family firms: linking resources, strategic planning and technological opportunities to performance. J Manag Stud 45:2650. https://doi.org/10.1111/j.1467-6486.2007.00717.x

Eisenhardt KM (1989) Agency theory: an assessment and review. Acad Manag Rev 14:57-74. https://doi. org/10.5465/amr.1989.4279003

Erkens DH, Van der Stede WA (2015) Strategy and control: findings from a set theoretical analysis of high-performance manufacturing firms. Marshall School of Business Working Paper No. ACC 03.13

Fama EF, Jensen MC (1983) Separation of ownership and control. J Law Econ 26:301-325. https://doi. org/10.1086/467037

Family Firm Institute (2017) Global data points. https://perma.cc/CF89-K2JB. Accessed 1 Aug 2019

Feldbauer-Durstmüller B, Duller C, Greiling D (2012) Strategic management accounting in Austrian family firms. Int J Bus Res 12:26-42

Filbeck G, Lee S (2000) Financial management techniques in family businesses. Fam Bus Rev 13:201216. https://doi.org/10.1111/j.1741-6248.2000.00201.x

Fisher JG (1998) Contingency theory, management control systems and firm outcomes: past results and future directions. Behav Res Account 10:47-64

Fiss PC (2007) A set-theoretic approach to organizational configurations. Acad Manag Rev 32:11801198. https://doi.org/10.5465/amr.2007.26586092

Fiss PC (2011) Building better causal theories: a fuzzy set approach to typologies in organization research. Acad Manag J 54:393-420. https://doi.org/10.5465/amj.2011.60263120

Flamholtz EG (1983) Accounting, budgeting and control systems in their organizational context: theoretical and empirical perspectives. Acc Organ Soc 8:153-169. https://doi.org/10.1016/03613682(83)90023-5

Fornell C, Larcker DF (1981) Evaluating structural equation models with unobservable variables and measurement error. J Mark Res 18:39-50. https://doi.org/10.2307/3151312

Garcia-Castro R, Aguilera RV (2014) Family involvement in business and financial performance: a set-theoretic cross-national inquiry. J Fam Bus Strat 5:85-96. https://doi.org/10.1016/j. jfbs.2014.01.006

Gerdin J, Greve J (2004) Forms of contingency fit in management accounting research-a critical review. Acc Organ Soc 29:303-326. https://doi.org/10.1016/s0361-3682(02)00096-X

Gerdin J, Greve J (2008) The appropriateness of statistical methods for testing contingency hypotheses in management accounting research. Acc Organ Soc 33:995-1009. https://doi.org/10.1016/j. aos.2007.07.003

Gersick CJG (1991) Revolutionary change theories: a multilevel exploration of the punctuated equilibrium paradigm. Acad Manag Rev 16:10-36. https://doi.org/10.5465/amr.1991.4278988

Giovannoni E, Maraghini MP, Riccaboni A (2011) Transmitting knowledge across generations: the role of management accounting practices. Fam Bus Rev 24:126-150. https://doi.org/10.1177/08944 86511406722

Goebel S, Weißenberger BE (2017a) Effects of management control mechanisms: towards a more comprehensive analysis. J Bus Econ 87:185-219. https://doi.org/10.1007/s11573-016-0816-6

Goebel S, Weißenberger BE (2017b) The relationship between informal controls, ethical work climates, and organizational performance. J Bus Ethics 141:505-528. https://doi.org/10.1007/s1055 1-015-2700-7

Gomez-Mejia LR, Cruz C, Berrone P, De Castro J (2011) The bind that ties: socioemotional wealth preservation in family firms. Acad Manag Ann 5:653-707. https://doi.org/10.1080/19416 520.2011 .593320

González-Cruz TF, Cruz-Ros S (2016) When does family involvement produce superior performance in SME family business? J Bus Res 69:1452-1457. https://doi.org/10.1016/j.jbusres.2015.10.124 
Gordon LA, Narayanan VK (1984) Management accounting systems, perceived environmental uncertainty and organization structure: an empirical investigation. Acc Organ Soc 9:33-47. https://doi. org/10.1016/0361-3682(84)90028-X

Grabner I, Moers F (2013) Management control as a system or a package? Conceptual and empirical issues. Acc Organ Soc 38:407-419. https://doi.org/10.1016/j.aos.2013.09.002

Gresov C, Drazin R (1997) Equifinality: functional equivalence in organization design. Acad Manag Rev 22:403-428. https://doi.org/10.5465/amr.1997.9707154064

Hall A, Melin L, Nordqvist M (2001) Entrepreneurship as radical change in the family business: exploring the role of cultural patterns. Fam Bus Rev 14:193-208. https://doi.org/10.111 $1 / j .1741-6248.2001 .00193 . x$

Hannan MT, Freeman J (1989) Organizational ecology. Harvard University Press, Cambridge

Hauck J, Suess-Reyes J, Beck S, Prügl R, Frank H (2016) Measuring socioemotional wealth in familyowned and-managed firms: a validation and short form of the FIBER Scale. J Fam Bus Strateg 7(3): 133-148

Helsen Z, Lybaert N, Steijvers T, Orens R, Dekker J (2017) Management control systems in family firms: a review of the literature and directions for the future. J Econ Surv 31:410-435. https://doi. org/10.1111/joes. 12154

Henri J-F (2006) Organizational culture and performance measurement systems. Acc Organ Soc 31:77103. https://doi.org/10.1016/j.aos.2004.10.003

Henri J-F (2009) Taxonomy of performance measurement systems. Adv Manag Acc 17:247-288. https:// doi.org/10.1108/S1474-7871(2009)0000017011

Hernandez M (2008) Promoting stewardship behavior in organizations: a leadership model. J Bus Ethics 80:121-128. https://doi.org/10.1007/s10551-007-9440-2

Hernandez M (2012) Toward an understanding of the psychology of stewardship. Acad Manag Rev 37:172-193. https://doi.org/10.5465/amr.2010.0363

Hiebl MRW, Feldbauer-Durstmüller B, Duller C (2013) The changing role of management accounting in the transition from a family business to a non-family business. J Acc Organ Change 9:119-154. https://doi.org/10.1108/18325911311325933

Hiebl MRW, Duller C, Feldbauer-Durstmüller B, Ulrich P (2015) Family influence and management accounting usage-findings from Germany and Austria. Schmalenbach Bus Rev 67:368-404. https ://doi.org/10.1007/bf03396880

Hoque Z, James W (2000) Linking balanced scorecard measures to size and market factors: impact on organizational performance. J Manag Acc Res 12:1-17. https://doi.org/10.2308/jmar.2000.12.1.1

IFERA (2003) Family businesses dominate: International Family Enterprise Research Academy. Fam Bus Rev 16:235-240. https://doi.org/10.1177/08944865030160040201

Jensen MC, Meckling WH (1976) Theory of the firm: managerial behavior, agency costs, and ownership structure. J Financ Econ 3:305-360. https://doi.org/10.1007/978-94-009-9257-3_8

Khandwalla PN (1972) The effect of different types of competition on the use of management controls. J Acc Res 10:275-285. https://doi.org/10.2307/2490009

Klein SB, Astrachan JH, Smyrnios KX (2005) The F-PEC scale of family influence: construction, validation, and further implication for theory. Entrep Theory Pract 29:321-339. https://doi.org/10.111 $1 / \mathrm{j} .1540-6520.2005 .00086 . \mathrm{x}$

Kleine C, Weißenberger BE (2014) Leadership impact on organizational commitment: the mediating role of management control systems choice. J Manag Control 24:241-266. https://doi.org/10.1007/ s00187-013-0181-3

Koufteros X, Verghese A, Lucianetti L (2014) The effect of performance measurement systems on firm performance: a cross-sectional and a longitudinal study. J Oper Manag 32:313-336. https://doi. org/10.1016/j.jom.2014.06.003

Kruis A-M, Speklé RF, Widener SK (2016) The levers of control framework: an exploratory analysis of balance. Manag Acc Res 32:27-44. https://doi.org/10.1016/j.mar.2015.12.002

Lee J (2006) Family firm performance: further evidence. Fam Bus Rev 19:103-114. https://doi.org/10.11 11/j.1741-6248.2006.00060.x

Lussier RN, Sonfield MC (2010) A six-country study of first-, second-, and third-generation family businesses. Int J Entrep Behav Res 16:414-436. https://doi.org/10.1108/13552551011071869

Madison K, Holt DT, Kellermanns FW, Ranft AL (2016) Viewing family firm behavior and governance through the lens of agency and stewardship theories. Fam Bus Rev 29:65-93. https://doi. org/10.1177/0894486515594292 
Madison K, Kellermanns FW, Munyon TP (2017) Coexisting agency and stewardship governance in family firms: an empirical investigation of individual-level and firm-level effects. Fam Bus Rev 30:347-368. https://doi.org/10.1177/0894486517727422

Malmi T, Brown DA (2008) Management control systems as a package-opportunities, challenges and research directions. Manag Acc Res 19:287-300. https://doi.org/10.1016/j.mar.2008.09.003

Merchant KA, Van der Stede WA (2017) Management control systems: performance measurement, evaluation and incentives. Financial Times/Prentice Hall, Harlow

Meyer AD, Tsui AS, Hinings CR (1993) Configurational approaches to organizational analysis. Acad Manag J 36:1175-1195. https://doi.org/10.2307/256809

Miller D, Le Breton-Miller I (2006) Family governance and firm performance: agency, stewardship, and capabilities. Fam Bus Rev 19:73-87. https://doi.org/10.1111/j.1741-6248.2006.00063.x

Misangyi VF, Acharya AG (2014) Substitutes or complements? A configurational examination of corporate governance mechanisms. Acad Manag J 57:1681-1705. https://doi.org/10.5465/amj.2012.0728

Moores K, Mula J (2000) The salience of market, bureaucratic, and clan controls in the management of family firm transitions: some tentative Australian evidence. Fam Bus Rev 13:91-106. https://doi. org/10.1111/j.1741-6248.2000.00091.x

Moores K, Yuen S (2001) Management accounting systems and organizational configuration: a life-cycle perspective. Acc Organ Soc 26:351-389. https://doi.org/10.1016/S0361-3682(00)00040-4

O'Boyle EH, Pollack JM, Rutherford MW (2012) Exploring the relation between family involvement and firms' financial performance: a meta-analysis of main and moderator effects. J Bus Ventur 27:1-18. https://doi.org/10.1016/j.jbusvent.2011.09.002

Otley DT (1980) The contingency theory of management accounting: achievement and prognosis. Acc Organ Soc 5:413-428. https://doi.org/10.1016/0361-3682(80)90040-9

Pearson AW, Marler LE (2010) A leadership perspective of reciprocal stewardship in family firms. Entrep Theory Pract 34:1117-1124. https://doi.org/10.1111/j.1540-6520.2010.00416.x

Pindado J, Requejo I (2015) Family business performance from a governance perspective: a review of empirical research. Int J Manag Rev 17:279-311. https://doi.org/10.1111/ijmr.12040

Pittino D, Barroso Martínez A, Chirico F, Sanguino Galván R (2018) Psychological ownership, knowledge sharing and entrepreneurial orientation in family firms: the moderating role of governance heterogeneity. J Bus Res 84:312-326. https://doi.org/10.1016/j.jbusres.2017.08.014

Prencipe A, Bar-Yosef S, Dekker HC (2014) Accounting research in family firms: theoretical and empirical challenges. Eur Acc Rev 23:361-385. https://doi.org/10.1080/09638180.2014.895621

Quinn RE, Rohrbaugh J (1981) A competing values approach to organizational effectiveness. Public Prod Rev 5:122-140. https://doi.org/10.2307/3380029

Ragin CC (2000) Fuzzy-set social science. University of Chicago Press, Chicago

Ragin CC (2006) Set relations in social research: evaluating their consistency and coverage. Polit Anal 14:291-310. https://doi.org/10.1093/pan/mpj019

Ragin CC (2008) Redesigning social inquiry: fuzzy sets and beyond. University of Chicago Press, Chicago

Ragin CC, Fiss PC (2008) Net effects analysis versus configurational analysis: an empirical demonstration. In: Ragin CC (ed) Redesigning social inquiry: fuzzy sets and beyond. University of Chicago Press, Chicago, pp 190-212

Ray CA (1986) Corporate culture: the last frontier of control. J Manag Stud 23(3):287-297. https://doi. org/10.1111/j.1467-6486.1986.tb00955.x

Rhoades L, Eisenberger R (2002) Perceived organizational support: a review of the literature. J Appl Psychol 87:698-714. https://doi.org/10.1037/0021-9010.87.4.698

Rihoux B, Marx A (2013) QCA, 25 years after "The Comparative Method": mapping, challenges, and innovations-mini-symposium. Polit Res Q 66:167-235. https://doi.org/10.1177/1065912912 468269

Roberts J, Scapens R (1985) Accounting systems and systems of accountability-understanding accounting practices in their organisational contexts. Acc Organ Soc 10:443-456. https://doi. org/10.1016/0361-3682(85)90005-4

Rutherford MW, Kuratko DF, Holt DT (2008) Examining the link between "Familiness" and performance: can the F-PEC untangle the family business theory jungle? Entrep Theory Pract 32:10891109. https://doi.org/10.1111/j.1540-6520.2008.00275.x

Samara G, Berbegal-Mirabent J (2018) Independent directors and family firm performance: does one size fit all? Int Entrep Manag J 14:149-172. https://doi.org/10.1007/s11365-017-0455-6 
Samara G, Jamali D, Sierra V, Parada MJ (2017) Who are the best performers? The environmental social performance of family firms. J Fam Bus Strat 9:33-43. https://doi.org/10.1016/j.jfbs.2017.11.004

Schneider CQ, Wagemann C (2012) Set-theoretic methods for the social sciences: a guide to qualitative comparative analysis. Cambridge University Press, Cambridge

Schulze WS, Lubatkin MH, Dino RN, Buchholtz AK (2001) Agency relationships in family firms: theory and evidence. Organ Sci 12:99-116. https://doi.org/10.1287/orsc.12.2.99.10114

Schulze WS, Lubatkin MH, Dino RN (2002) Altruism, agency, and the competitiveness of family firms. Manag Decis Econ 23:247-259. https://doi.org/10.1002/mde.1064

Senftlechner D, Hiebl MR (2015) Management accounting and management control in family businesses: past accomplishments and future opportunities. J Acc Organ Change 11:573-606. https://doi. org/10.1108/JAOC-08-2013-0068

Simons R (1995) Levers of control: how managers use innovative control systems to drive strategic renewal. Harvard Business School Press, Boston

Skaaning S-E (2011) Assessing the robustness of crisp-set and fuzzy-set QCA results. Soc Methods Res 40:391-408. https://doi.org/10.1177/0049124111404818

Songini L, Gnan L (2015) Family involvement and agency cost control mechanisms in family small and medium-sized enterprises. J Small Bus Manag 53:748-779. https://doi.org/10.1111/jsbm.12085

Songini L, Morelli C, Vola P (2018) Managerial control systems in family business: state of the art. In: Epstein M, Verbeeten F, Widener SK (eds) Performance measurement and management control: the relevance of performance measurement and management control research (Studies in Managerial and Financial Accounting), vol 33. Emerald Publishing Limited, Bingley, pp 193-220. https:// doi.org/10.1108/S1479-351220180000033008

Speckbacher G, Wentges P (2012) The impact of family control on the use of performance measures in strategic target setting and incentive compensation: a research note. Manag Acc Res 23:34-46. https://doi.org/10.1016/j.mar.2011.06.002

Steier L (2001) Family firms, plural forms of governance, and the evolving role of trust. Fam Bus Rev 14:353-368. https://doi.org/10.1111/j.1741-6248.2001.00353.x

Sy T, Côté S, Saavedra R (2005) The contagious leader: Impact of the leader's mood on the mood of group members, group affective tone, and group processes. J Appl Psychol 90:295-305. https://doi. org/10.1037/0021-9010.90.2.295

Tessier S, Otley D (2012) A conceptual development of Simons' levers of control framework. Manag Acc Res 23:171-185. https://doi.org/10.1016/j.mar.2012.04.003

The Foundation for Family Businesses (2016) Definition of the family business. https://www.familienun ternehmen.de/en/definition-family-businesses. Accessed 7 Feb 2020

The Foundation for Family Businesses (2019) Dates, numbers, facts. https://www.familienunternehmen. de/en/data-numbers-facts. Accesses 7 Feb 2020

Thiem A, Baumgartner M, Bol D (2016) Still lost in translation! A correction of three misunderstandings between configurational comparativists and regressional analysts. Comp Polit Stud 49:742-774. https://doi.org/10.1177/0010414014565892

Tsao C-W, Chen S-J, Lin C-S, Hyde W (2009) Founding-family ownership and firm performance: the role of high-performance work systems. Fam Bus Rev 22:319-332. https://doi.org/10.1177/08944 86509339322

Upton N, Teal EJ, Felan JT (2001) Strategic and business planning practices of fast growth family firms. J Small Bus Manag 39:60-72. https://doi.org/10.1111/0447-2778.00006

Vallejo MC (2009) The effects of commitment of non-family employees of family firms from the perspective of stewardship theory. J Bus Ethics 87:379-390. https://doi.org/10.1007/s10551-008-9926-6

Van der Stede WA, Mark Young S, Xiaoling Chen C (2006) Doing management accounting survey research. In: Chapman CS, Hopwood AG, Shields MD (eds) Handbook of management accounting research, 1st edn. Elsevier, Oxford, pp 445-478. https://doi.org/10.1016/s1751-3243(06)01018-2

Wagemann C, Buche J, Siewert MB (2016) QCA and business research: work in progress or a consolidated agenda? J Bus Res 69:2531-2540. https://doi.org/10.1016/j.jbusres.2015.10.010

Widener SK (2007) An empirical analysis of the levers of control framework. Acc Organ Soc 32:757788. https://doi.org/10.1016/j.aos.2007.01.001

Woodside AG (2013) Moving beyond multiple regression analysis to algorithms: calling for adoption of a paradigm shift from symmetric to asymmetric thinking in data analysis and crafting theory. J Bus Res 66:463-472. https://doi.org/10.1016/j.jbusres.2012.12.021

Woodside AG, Ko E, Huan T-C (2012) The new logic in building isomorphic theory of management decision realities. Manag Decis 50:765-777. https://doi.org/10.1108/00251741211227429 
Zahra SA, Hayton JC, Neubaum DO, Dibrell C, Craig J (2008) Culture of family commitment and strategic flexibility: the moderating effect of stewardship. Entrep Theory Pract 32:1035-1054. https:// doi.org/10.1111/j.1540-6520.2008.00271.x

Zammuto RF, Krakower JY (1991) Quantitative and qualitative studies of organizational culture. In: Pasmore WA, Woodman RW (eds) Research in organizational change and development: an annual series featuring advances in theory, methodology and research. JAI Press Inc, Greenwich, pp 83-114

Publisher's Note Springer Nature remains neutral with regard to jurisdictional claims in published maps and institutional affiliations.

\section{Affiliations}

\section{Stefanie Einhorn ${ }^{1} \cdot$ Xaver Heinicke $^{1} \cdot$ Thomas W. Guenther $^{1}$}

Stefanie Einhorn

Stefanie.Einhorn@tu-dresden.de

Xaver Heinicke

Xaver.Heinicke@tu-dresden.de

1 Faculty of Business and Economics, Technische Universität Dresden, 01062 Dresden, Germany 